\title{
A Global Ge Isotope Budget
}

J. Jotautas Baronas ${ }^{1 *}$, Douglas E. Hammond ${ }^{1}$, James McManus ${ }^{2,3}$, C. Geoffrey Wheat $^{4}$, and Christopher Siebert ${ }^{5}$

${ }^{1}$ Department of Earth Sciences, University of Southern California, Los Angeles, CA 90089, USA

*Corresponding author: jotautas.baronas@gmail.com

${ }^{2}$ CEOAS, Oregon State University, Corvallis, OR 97331, USA

${ }^{3}$ Present address: Bigelow Laboratory for Ocean Sciences, East Boothbay, ME 04544, USA

${ }^{4}$ Institute of Marine Science, University of Alaska Fairbanks, Moss Landing, CA 95039, USA

${ }^{5}$ GEOMAR, Helmholtz Centre for Ocean Research, 24148 Kiel, Germany

\begin{abstract}
We present measurements of Ge isotope composition and ancillary data for samples of river water, low- and high-temperature hydrothermal fluids, and seawater. The dissolved $\delta^{74} \mathrm{Ge}$ composition of analyzed rivers ranges from 2.0 to $5.6 \%$, which is significantly heavier than previously determined values for silicate rocks $\left(\delta^{74} \mathrm{Ge}=0.4-0.7 \%\right.$, Escoube et al., GGR, 36(2), 2012) from which dissolved Ge is primarily derived. An observed negative correlation between riverine $\mathrm{Ge} / \mathrm{Si}$ and $\delta^{74} \mathrm{Ge}$ signatures suggests that the primary $\delta^{74} \mathrm{Ge}$ fractionation mechanism during rock weathering is the preferential incorporation of light isotopes into secondary weathering products. High temperature $\left(>150^{\circ} \mathrm{C}\right)$ hydrothermal fluids analyzed in this study have $\delta^{74} \mathrm{Ge}$ of $0.7-1.6 \%$, most likely fractionated during fluid equilibration with quartz in the reaction zone. Low temperature $\left(25-63{ }^{\circ} \mathrm{C}\right)$ hydrothermal fluids are heavier $\left(\delta^{74} \mathrm{Ge}\right.$ between 2.9 and $4.1 \%$ ) and most likely fractionated during Ge precipitation with hydrothermal clays. Seawater from the open ocean has a $\delta^{74} \mathrm{Ge}_{\mathrm{sw}}$ value of $3.2 \pm 0.4 \%$, and is indistinguishable among the different ocean basins at the current level of precision. This
\end{abstract}


value should be regulated over time by the isotopic balance of Ge sources and sinks, and a new compilation of these fluxes is presented, along with their estimated isotopic compositions. Assuming steady-state, non-opal Ge sequestration during sediment authigenesis likely involves isotopic fractionation $\Delta^{74} \mathrm{Ge}_{\text {solid-solution }}$ that is $-0.6 \pm 1.8 \%$.

\section{Introduction}

\subsection{Ge biogeochemistry and $\mathrm{Ge} / \mathrm{Si}$}

Germanium $(\mathrm{Ge})$ is a trace element with electronic structure and chemical behavior similar to silicon ( $\mathrm{Si}$ ), allowing Ge to substitute for $\mathrm{Si}$ in mineral and amorphous silicates at parts-permillion (ppm) levels (Burton et al., 1959). Differences in the chemical behavior of Ge and Si are primarily caused by the larger atomic radius of $\mathrm{Ge}$, which allows it to form longer bonds with oxygen and sulfur (Bernstein, 1985). As a result, Ge preferentially partitions into poorlyinterlinked phyllosilicates rather than highly-interlinked tectosilicates, and is also able to enter octahedral coordination sites in Fe oxides and sulfides, enabling the use of the Ge to Si ratio (Ge/Si) as a geochemical tracer. For example, during silicate rock weathering the formation of secondary products, such as metal oxides and aluminosilicate clays, incorporates Ge either structurally or through adsorption (Pokrovsky et al., 2006) with a higher Ge/Si (commonly 4-6 $\mu \mathrm{mol} / \mathrm{mol}$ but sometimes in excess of $100 \mu \mathrm{mol} / \mathrm{mol}$ )(Kurtz et al., 2002; Derry et al., 2006; Scribner et al., 2006; Kurtz et al., 2011) relative to the initial bedrock (typically 1-3 $\mu \mathrm{mol} / \mathrm{mol}$ )(Mortlock and Froelich, 1987; Murnane and Stallard, 1990; Kurtz et al., 2002). As a result, the dissolved species (germanic and silicic acid, or $\mathrm{Ge}(\mathrm{OH})_{4}$ and $\left.\mathrm{Si}(\mathrm{OH})_{4}\right)$ in river waters occur at a lower ratio, with $\mathrm{Ge} / \mathrm{Si}_{\text {riv }}$ ranging from 0.1 to $3 \mu \mathrm{mol} / \mathrm{mol}$ (Murnane and Stallard, 1990; Froelich et al., 1992; Chillrud et al., 1994; Filippelli et al., 2000; Anders et al., 2003; Meek et al., 2016). In hydrothermal fluids, the $\mathrm{Ge} / \mathrm{Si}$ ratio is largely controlled by the difference in thermodynamic properties of aqueous and solid $\mathrm{Ge}$ and $\mathrm{Si}$ compounds between which the equilibrium is established at high temperatures (Pokrovski and Schott, 1998; Evans and Derry, 2002). Due to generally higher solubility of Ge 
minerals (e.g., $\mathrm{GeO}_{2}$ vs. $\mathrm{SiO}_{2}$ ), as well as the reluctance of $\mathrm{Ge}$ to enter the highly-interlinked lattice of quartz precipitated during cooling, hydrothermal fluids tend have much higher $\mathrm{Ge} / \mathrm{Si}$, commonly 4-25 $\mu \mathrm{mol} / \mathrm{mol}$ but reaching up to $1000 \mu \mathrm{mol} / \mathrm{mol}$ in some terrestrial hot springs (Arnorsson, 1984; Mortlock et al., 1993; Evans and Derry, 2002; Wheat and McManus, 2005, 2008; Escoube et al., 2015).

In the ocean, $\mathrm{Ge}$ is taken up and incorporated into biogenic silica (bSi) by diatoms, sponges, and other biosilicifiers, leading to a tight coupling between Ge and Si concentrations, nutrient-like Ge profiles, and a relatively constant deep water Ge/Si of $0.76 \mu \mathrm{mol} / \mathrm{mol}$ (Froelich et al., 1985a, 1989; Ellwood et al., 2006; Sutton et al., 2010). Ge removal from the ocean occurs through bSi burial and through Ge sequestration from marine porewaters into certain authigenic minerals (termed "non-opal burial"). This latter process has been observed to occur in rapidly accumulating shallow-redox marine sediments, most commonly in continental margin areas and suboxic basins (Hammond et al., 2000; King et al., 2000; McManus et al., 2003; Baronas et al., 2016). Although the exact Ge-incorporating phases have not been identified, similarly to continental weathering, both iron oxyhydroxides and aluminosilicates have been implicated.

Germanium residence time in seawater is similar to that of $\mathrm{Si}$, that is, $<10 \mathrm{ky}$ (Hammond et al., 2004b). Diatom Ge/Si paleorecords indicate large shifts in the oceanic Ge/Si signature over glacial-interglacial cycles (Froelich et al., 1989; Mortlock et al., 1991) and throughout the Cenozoic (Shemesh et al., 1989). These shifts could reflect variations in the non-opal Ge burial flux, driven by changes in ocean water temperature (Hammond et al., 2004b) and detrital inputs or sediment redox conditions (Baronas et al., 2016), which could shed light on changes in biogenic silica cycling and the role that diatom productivity plays in glacial-interglacial climate variability. Another possibility is that the oceanic $\mathrm{Ge} / \mathrm{Si}$ is primarily reflecting the riverine $\mathrm{Ge} / \mathrm{Si}$ signature and flux, which would imply large changes in the silicate weathering flux over glacial-interglacial timescales (Froelich et al., 1992), suggesting a high sensitivity of silicate weathering to climate (Vance et al., 2009), in contrast to many current models (Foster and Vance, 2006; Opfergelt et al., 2013b,a; von Blanckenburg et al., 2015; Frings et al., 2016). In addition, better constraints on 
how weathering processes influence the elemental and isotopic composition of Ge and other trace elements would allow for a more robust interpretation of paleorecords spanning million-year and longer timescales, providing further clues on the relationship between climate and the intensity of silicate weathering (e.g., Raymo and Ruddiman, 1992; Misra and Froelich, 2012; Li and Elderfield, 2013). Variations in the Ge isotope composition of seawater may help resolve these questions, if the various Ge sources and sinks have distinct isotopic signatures.

\subsection{Ge isotopes}

Germanium has five naturally occurring isotopes: the stable isotopes are ${ }^{70} \mathrm{Ge}(20.4 \%$ abundance), ${ }^{72} \mathrm{Ge}(27.3 \%),{ }^{73} \mathrm{Ge}(7.8 \%)$, and ${ }^{74} \mathrm{Ge}(36.7 \%)$, while ${ }^{76} \mathrm{Ge}(7.8 \%)$ is slightly radioactive (half life of $1.55 \times 10^{21}$ years)(Klapdor-Kleingrothaus et al., 2001; de Laeter et al., 2003). Ge isotopic composition is discussed and reported here as $\delta^{74} \mathrm{Ge}$, where

$$
\delta^{74} \mathrm{Ge}=\frac{\left({ }^{74} \mathrm{Ge} /{ }^{70} \mathrm{Ge}\right)_{\text {sample }}}{\left({ }^{74} \mathrm{Ge} /{ }^{70} \mathrm{Ge}\right)_{\text {NIST3120a }}}-1
$$

expressed in \%o, consistent with the recent literature (Escoube et al., 2012; Pokrovsky et al., 2014; Belissont et al., 2014; Escoube et al., 2015). Previous work has shown that different types of silicate rocks have similar ${ }^{74} \mathrm{Ge}$ composition of 0.40-0.68 \%o(Rouxel et al., 2006; Escoube et al., 2012). Theoretical and experimental studies have demonstrated that in almost all cases the light Ge isotopes are preferentially incorporated into mineral phases (Li et al., 2009; Li and Liu, 2010; Pokrovsky et al., 2014). Furthermore, hydrothermal fluids from the East Pacific Rise and the Loihi seamount (0.61 to $2.20 \%$ )(Escoube et al., 2015) and terrrestrial hotsprings in the Cascade mountain range (1.65 to $3.29 \%$, recalculated here relative to NIST 3120a)(Siebert et al., 2006, 2011) were also shown to be isotopically heavy relative to the oceanic crust, indicating the incorporation of light Ge in hydrothermal Fe oxide and sulfide minerals, which have been observed to have $\delta^{74} \mathrm{Ge}$ as low as $-4.71 \pm 0.18 \%$ (Escoube et al., 2015). In contrast, various natural phases formed from seawater are all significantly heavier, e.g. iron formations $(1.09 \pm 0.09 \%)$, authigenic glauconite $(2.44 \pm$ 
$0.15 \%$ ), siliceous sponge spicules (1.56-2.60\%) (all reported by Rouxel et al., 2006; Escoube et al., 2012), and diatom frustules (3.10-3.63 \%o) (Mantoura, 2006), suggesting either an additional isotopically heavy Ge source, or strong fractionation during Ge removal from the ocean. Therefore, the isotopic characterization of oceanic Ge fluxes other than the high-temperature hydrothermal input is needed if the global Ge isotope budget is to be constrained and seawater $\delta^{74} \mathrm{Ge}$ composition established as a useful proxy.

With this in mind, we have developed methods to analyze the isotope composition of Ge in water samples with very low Ge concentrations (as low as $\sim 20 \mathrm{pM}$ ). We measured the dissolved Ge isotopic composition of several rivers, seawater from different ocean basins, and hydrothermal fluids from both high- and low-temperature systems, focusing on the previously uncharacterized sediment-covered Juan de Fuca ridge. These data, along with previously published data, has been used to construct a preliminary Ge isotope budget for the global ocean and predict the isotopic signature associated with non-opal Ge burial.

\section{Methods}

\subsection{Sample collection}

For river water analysis, 2-4L samples were collected between 2008 and 2013 during field expeditions in California, Hawaii, and Peru (Table 1). Peruvian river samples were collected in polyethylene bags, filtered on-site through $0.2 \mu \mathrm{m}$ polyethersulfone (PES) membrane and acidified, spiked, and co-precipitated in the field (see section 2.3). The other samples were filtered either on-site or back in the laboratory within $48 \mathrm{~h}$ of collection through 0.2 or $0.4 \mu \mathrm{m}$ PES or polyethylene (PE) membrane.

For seawater analysis, the Atlantic Ocean samples were collected at the Bermuda Atlantic Ocean Time Series station (BATS) during the June 2008 GEOTRACES intercalibration cruise aboard the R/V Knorr. 250L of the GDI sample was collected into multiple Niskin bottles on a trace metalclean rosette. The GPrI sample was collected into a 12L GO-Flo bottle. Samples were filtered in 
a clean van using $0.2 \mu \mathrm{m}$ Pall Acropak capsule and acidified immediately with trace metal-clean HCl. Additional details and data are given in Boyle et al. (2012). The Cascadia basin samples were collected into 10L Niskin bottles in August 2006 during a cruise aboard R/V Thomas G. Thompson, filtered using $0.45 \mu \mathrm{m}$ Whatman-Nuclepore Track-Etch membrane and acidified back in the lab. Additional details and data are given in Esther et al. (2010).

The Gulf of Mexico samples were collected aboard R/V Endeavor in August 2011. The Ge and Si cycling in the water column and the sediments have been previously described in Baronas et al. (2016). Briefly, seawater samples were collected into 10L Niskin bottles and filtered on-deck through AcroPak 200 Capsule filters with a 0.8/0.2 $\mu \mathrm{m}$ Supor membrane. Sediment cores were collected using a multicorer, and pore waters were sampled using $0.15 \mu \mathrm{m}$ pore size Rhizons (Rhizosphere Research Products, Wageningen, The Netherlands) inside a cold van. Whole cores were incubated as previously described by Hammond et al. (2004a). Briefly, sediment cores with $\sim 1 \mathrm{~L}$ of overlying water were sealed off from the atmosphere, and the overlying water was stirred using a magnetic stir bar. After 5 days, the overlying water was collected and immediately filtered through a $0.4 \mu \mathrm{m}$ PES filter.

All river and seawater samples were stored at 3-4 ${ }^{\circ} \mathrm{C}$ shortly after collection. Some samples were acidified immediately after filtration with trace metal-clean $\mathrm{HCl}$ or $\mathrm{HNO}_{3}$ and others only prior to adding double spike (see below). Tests showed that acidification was unnecessary to keep $\mathrm{Ge}$ and $\mathrm{Si}$ in solution, based on the stable Ge and $\mathrm{Si}$ concentrations of unacidified samples stored refrigerated in the dark for several years.

The hydrothermal fluid samples were collected and processed during four separate expeditions. All samples were collected with Walden-Weiss titanium samplers deployed from a submersible. Juan de Fuca Ridge (JdFR) flank samples were collected from sites of natural focused venting at the Baby Bare outcrop (Wheat and Mottl, 2000), and boreholes drilled through sediment into the basalt basement rock tens of kilometers away during ODP Leg 168 (Elderfield et al., 1999; Wheat et al., 2004). JdFR axial fluids (Middle Valley) were collected from vent chimneys exhibiting focused flow (Butterfield et al., 1994), and Loihi fluids were collected in 1996 from buoyant jets 
in the Pele's Pit (Wheat et al., 2000). All samples were filtered though a $0.4 \mu \mathrm{m}$ membrane immediately upon recovery to remove any entrained rust in the case of borehole samples, sediment and microbial mats in the case of low temperature vents, and vent chimney flakes in the case of high-temperature fluids. Since all the fluids in this study were cooler than $200{ }^{\circ} \mathrm{C}$ and did not contain high concentrations of dissolved sulfide, Ge is unlikely to be scavenged during cooling of the fluids prior to filtration. All samples were acidified with trace metal-clean $\mathrm{HCl}$ prior to storage and analysis and the high-temperature (Loihi and Middle Valley) fluids were additionally diluted 1:20 with $10 \% \mathrm{HCl}$ to prevent amorphous Si precipitation.

\subsection{Elemental concentration analysis}

Si concentrations were measured using molybdate blue colorimetry (Mullin and Riley, 1955) in seawater and river water samples and with ICP-AES in hydrothermal fluids, with a typical 2 S.D. uncertainty of $<5 \%$. Ge concentrations were measured using isotope dilution hydride generation inductively coupled plasma mass spectrometry (ID-HG-IPC-MS) on a Thermo Element 2, as described in Mortlock and Froelich (1996) and modified by Hammond et al. (2000) and Baronas et al. (2016), with a typical 2 S.D. uncertainty of $<5 \%$. Accuracy and precision were assessed by measurements of NIST 3120a $(\mathrm{n}=26)$, as well as internal seawater $(\mathrm{n}=36)$ and river water $(\mathrm{n}$ $=17$ ) standards analyzed alongside the samples. The procedural blank was variable but typically around 1-2 pg (15-30 fmol) Ge.

River water major cation concentration measurements were done on a Microwave Plasma Atomic Emission Spectrometer (MP-AES; Agilent, USA). Accuracy and precision (2 S.D. better than $10 \%$ for all analytes, $n=4$ ) were assessed by measuring ION-915 certified reference material (Environment Canada).

\subsection{Ge isotope analysis}

Ge isotope composition was analyzed using a previously described double-spike technique (Siebert et al., 2006, 2011). Briefly, a double isotope spike $\left({ }^{73} \mathrm{Ge} /{ }^{70} \mathrm{Ge}\right.$ at a ratio of 1) was added 
to each sample to obtain a spike/sample ratio between 1 and 3 (total Ge mass). Volumes of sample used ranged from 0.5 to $5 \mathrm{~L}$ and contained between 3 and $40 \mathrm{ng}$ (40-550 pmol) of Ge. The double spike used here was calibrated previously as described in Siebert et al. (2006, 2011). All samples were allowed to equilibrate with the spike for 24 hours or longer. At this stage samples were also acidified to $\mathrm{pH} 2$ (where this was not done previously) and stirred to degas $\mathrm{CO}_{2}$ while equilibrating with the spike. Due to low natural Ge concentrations in low-temperature fluids, pre-concentration was required prior to $\mathrm{Ge}$ isotope analysis. In the case of freshwater samples, a purified $\mathrm{MgCl}_{2}$ or $\mathrm{Mg}\left(\mathrm{NO}_{3}\right)_{2}$ solution was added to produce a final $\mathrm{Mg}$ concentration of 20-120 mM. Ge in seawater and freshwater samples was then co-precipitated with $\mathrm{Mg}(\mathrm{OH})_{2}$ by raising the $\mathrm{pH}$ to 9-10 with a stream of $\mathrm{NH}_{3}$ vapor or by adding trace-grade $\mathrm{NaOH}$ when precipitating in the field. The precipitate was collected by decanting and centrifuging, and redissolved using teflon-distilled $\mathrm{HNO}_{3}$.

The hydrothermal samples were analyzed without co-precipitation, using the method described in Siebert et al. (2006). Briefly, the hydride generation was done online using a continuous hydride generator, where $\mathrm{NaBH}_{4}$ and sample are mixed at a constant rate and the resulting hydride is carried by a Helium gas stream into the instrument. Each sample was bracketed with a liquid in-house standard. The isotope composition of this standard and the samples was related to NIST 3120a through measurements of the BCR rock reference material, determined to be $1.20 \pm 0.18 \%$ (2 S.D., $\mathrm{n}=9$ ) relative to the in-house OSU standard. The isotope composition of all bracketing standards used is given in Supplementary Table S1 and Fig. S1.

Methylated Ge species are unreactive and do not participate in the inorganic Ge cycling to any appreciable degree but are present in relatively high concentrations in seawater (Lewis et al., 1989). Therefore, it is necessary to ensure the removal of methylated Ge prior to isotope Ge analysis of seawater. To achieve this, the hydride generation of river and seawater samples was done offline by using a $\mathrm{He}$ stream to capture the evolved $\mathrm{GeH}_{4}$ in a liquid $\mathrm{N}_{2}$ cold trap, based on the method of Mortlock and Froelich (1996). When the cold trap was allowed to warm to room temperature, inorganic and methylated Ge hydrides present in seawater eluted separately, allowing the collection of the inorganic fraction in a Tedlar bag. The separation was ensured by monitoring the elution of 
the methylated Ge hydrides using ICP-MS. The collected inorganic $\mathrm{GeH}_{4}$ was kept in Tedlar bags for several days until isotope analysis. Tests showed that $\mathrm{GeH}_{4}$ diffusion from Tedlar bags was negligible over the course of several weeks. Prior to isotope analysis, the $\mathrm{GeH}_{4}$ was diluted with He and injected into the instrument by applying steady pressure to the bag. Additional details on sample preparation and hydride generation are given in the Supplementary Material.

River water and seawater analyses were interspersed with similarly prepared NIST 3120a standard, as well as two other Ge isotope standards to monitor accuracy and instrument drift (Table $\mathrm{S} 1$, Fig. S1). In the case of seawater and river samples, a small $(0.4 \mathrm{mV})$ interference at $\mathrm{m} / \mathrm{z} 72$ was observed, most likely from ${ }^{40} \mathrm{Ar}^{16} \mathrm{O}_{2}{ }^{+}$or ${ }^{36} \mathrm{Ar}_{2}{ }^{+}$. A similar effect but for $\mathrm{m} / \mathrm{z} 70$ was observed previously by Rouxel et al. (2006). To correct for this interference, each sample was measured at a range of signal intensities by adjusting the gas flow out of the Tedlar bag (Supp. Fig S3). The ${ }^{72} \mathrm{Ge}$ signal was plotted against the other isotope signals (Supp. Fig. S4) and a linear regression was used to calculate the interference-free 72/70, 72/73, and 72/74 ratios for the analyte (Supp. Fig. S2). The isotope composition of each sample and standard was then calculated using the double-spike data reduction scheme outlined previously by Siebert et al. (2006, 2011).

All measurements were made on a Nu Instruments HR MC-ICP-MS (Wrexham, North Wales, UK) in the W.M. Keck Collaboratory at Oregon State University. The voltage was measured in static mode and at low resolution in cups L2, C, H2, and $\mathrm{H} 4$ for ${ }^{70} \mathrm{Ge},{ }^{72} \mathrm{Ge},{ }^{73} \mathrm{Ge}$, and ${ }^{74} \mathrm{Ge}$, respectively. The hydrothermal fluid samples were analyzed in July 2006 and the seawater and river samples over three analytical sessions in 2013-2014. The uncertainty of all samples is reported either as 2 S.D. reproducibility of the bracketing standard during the given analytical session, or 2 S.D. of 2-3 sample replicate measurements (some hydrothermal samples only), whichever is greater. 


\section{Results}

\subsection{Rivers}

The $\delta^{74} \mathrm{Ge}$ composition of rivers and streams sampled for this study $(\mathrm{n}=16)$ ranged between 2.0 and $5.6 \%$ (Table 1), significantly heavier than the $0.4-0.7$ of silicate rocks \%o (Rouxel et al., 2006; Escoube et al., 2012), indicating that river water $\delta^{74} \mathrm{Ge}$ is strongly fractionated relative to the bedrock source. The overlap in $\delta^{74} \mathrm{Ge}$ measured in rivers draining basalts, meta-sediments, and granites suggests that watershed lithology is not the primary factor governing the isotopic composition of dissolved Ge in rivers (Fig. 1). Samples taken from a single watershed along a steep morphological gradient from the Peruvian Andes to the Amazon foreland floodplain (see Ponton et al. (2014) for a detailed description of the study site), span most of the observed riverine $\delta^{74} \mathrm{Ge}$ range (Table 1 ). The $\delta^{74} \mathrm{Ge}$ composition of river water correlates well with dissolved Ge concentration and Ge/Si ratio, especially when samples affected by human activities are excluded. The Lower Kern river sample exhibiting very high Ge/Si ratio was collected downstream of a dam reservoir (fed by both North and South forks of the Kern river), suggesting that Ge/Si is most likely affected by diatom growth in the reservoir.

\subsection{Seawater}

We have measured the isotopic composition of multiple seawater samples from various locations (total measurements $n=15$, unique samples $n=9)$. In addition, pore water $(n=1)$, and water from core incubations containing a mix of Ge from bottom water and Ge diffusing from sediments $(n=3)$ were analyzed. The isotope data, along with Ge/Si ratios and sample details are summarized in Table 2 and Fig. 2. Measured seawater $\delta^{74}$ Ge values range from $2.18 \pm 0.50$ to $3.48 \pm 0.35$ $\%$. The lightest values were found in the bottom waters in the northern Gulf of Mexico (GoMex) shelf, both in-situ and after core incubations. These values are similar to the Mississippi river signature (Table 1, Fig. 2), which is a major source of dissolved Ge and Si to the area. Atlantic and Pacific ocean deep water samples were in the narrow 3.07-3.48 \%o range, indistinguishable 
within uncertainty. The simple average \pm 2 S.D. of all measured deep water values is $3.24 \pm 0.44 \%$, which we propose as a preliminary average seawater composition. Finally, pore water from Gulf of Mexico continental slope sediments (90 m water depth) was indistinguishable from seawater.

\subsection{Hydrothermal fluids}

The hydrothermal fluids are enriched in Ge relative to ambient seawater, reaching concentrations of 10-500 nM, which are 100-5000 times higher than seawater. Our measured hydrothermal fluid $\delta^{74} \mathrm{Ge}$ values vary from $0.69 \pm 0.29$ to $4.09 \pm 1.27 \%$ (Table 3 ), expanding the range of previously determined values (Siebert et al., 2006, 2011; Escoube et al., 2015). Loihi seamount fluids reported in this study were collected only 3 months after a large eruption in 1996 that destroyed multiple previous vents and created what is now known as the Pele's Pit. These samples represent hot fluids $\left(160-200{ }^{\circ} \mathrm{C}\right)$ that are extremely concentrated in $\mathrm{Ge}(200-500 \mathrm{nM})$ and isotopically relatively close to basalt $\left(\delta^{74} \mathrm{Ge}=0.69-1.42 \%\right)$. These values are at the lower range of those reported for Loihi fluids collected in 2006-2007 (Escoube et al., 2015) but exhibit generally higher Ge/Si ratios (Fig. 3). Juan de Fuca ridge (JdFR) fluids sampled from a borehole at the Middle Valley site $\left(276{ }^{\circ} \mathrm{C}\right)$ exhibit similar Ge concentration $(250-260 \mathrm{nM})$ and isotopic composition $\left(\delta^{74} \mathrm{Ge}=1.5 \%\right)$ to fluids venting in the East Pacific Rise (EPR) (Escoube et al., 2015), despite exhibiting higher Ge/Si ratios than previously sampled high-temperature mid-ocean ridge fluids at EPR and JdFR (Mortlock and Froelich, 1986; Mortlock et al., 1993; Escoube et al., 2015).

Baby Bare is a basement rock outcrop on the eastern flank of the Juan de Fuca ridge, within what is otherwise a sediment-blanketed Cascadia basin. Here, typically diffuse low-temperature fluids are focused and discharge through a small, thermally extinct volcano (Mottl et al., 1998). Several boreholes have also been drilled through the sediment blanket during the ODP Leg 168 and upwelling fluids sampled from just within the basement rock (Elderfield et al., 1999). The basement temperature at which crust alteration occurs has been determined to be $43{ }^{\circ} \mathrm{C}$ for the ODP 1025 site and $63{ }^{\circ} \mathrm{C}$ for all the fluids presented here (Elderfield et al., 1999; Wheat and Mottl, 2000). Both the vent and the borehole fluids had Ge/Si similar to the Middle Valley fluids but much lower Ge 
concentrations $(9-22 \mathrm{nM})$ and some of the highest $\delta^{74} \mathrm{Ge}$ of all hydrothermal fluids analyzed to date, between 2.94 and $4.09 \%$ (Fig 3).

\section{Discussion}

\subsection{Rivers}

\subsubsection{Fractionation during weathering}

Considering that silicate rocks have $\delta^{74} \mathrm{Ge}$ of $\sim 0.6 \%$, the riverine data presented here (Table 1) imply an apparent $\Delta^{74} \mathrm{Ge}_{\text {solid-liquid }}$ fractionation factor that spans around -5 to $-2 \%$. However, it is more likely that the observed range of riverine $\delta^{74} \mathrm{Ge}$ values reflects the varying degrees of isotope fractionation as fluids in contact with rocks evolve, rather than a large range of actual $\Delta^{74} \mathrm{Ge}_{\text {solid-liquid }}$ fractionation factors. It has been shown that riverine $\mathrm{Ge} / \mathrm{Si}$ ratios are relatively insensitive to bedrock composition and are primarily controlled by weathering intensity, i.e. the fraction of material removed from a watershed in the dissolved phase (chemical weathering) relative to total denudation (the sum of chemical and physical weathering) (Mortlock and Froelich, 1987; Murnane and Stallard, 1990; Froelich et al., 1992). In low weathering intensity, fast eroding watersheds, the high rate of fresh mineral supply results in high solute concentrations, and the chemical composition of the streams is thought to be largely limited by weathering reaction kinetics (West et al., 2005). In this case, the dissolved Ge/Si and, we propose, $\delta^{74} \mathrm{Ge}$ composition should be strongly fractionated due to rapid precipitation of secondary weathering products, such as $\mathrm{Fe}$ and $\mathrm{Al}$ oxides and aluminosilicates. In slowly eroding watersheds fresh primary minerals become depleted, limiting solute concentrations and resulting in limited precipitation (or even dissolution) of secondary weathering products. In the latter case, riverine $\mathrm{Ge} / \mathrm{Si}$ and $\delta^{74} \mathrm{Ge}$ composition should more closely resemble the initial bedrock values.

Unfortunately, there is currently no $\delta^{74} \mathrm{Ge}$ data of secondary weathering products available to directly test the above hypothesis. However, the degree to which Ge has been removed from 
solution through secondary phase precipitation can be assessed by normalizing Ge concentration to a conservative solute that is not incorporated into secondary products, such as $\mathrm{Na}$ or other major cations. This approach has been previously employed to investigate $\mathrm{Si}$ and $\mathrm{Li}$ isotope behavior during weathering (Hughes et al., 2013; Dellinger et al., 2015). Fig. 4a demonstrates that rivers exhibiting lower $\mathrm{Ge} / \mathrm{Na}$ ratios are also isotopically the heaviest. Assuming relatively invariant silicate rock Ge/Na ratios and a Rayleigh type behavior, the relationship in Fig. 4a can be used to estimate the Ge isotope fractionation factor $\alpha_{\text {solid-liquid }}$ of $0.9992\left(\Delta^{74} \mathrm{Ge}_{\text {solid-liquid }}=-0.8 \%\right)$. To minimize the potential effect of lithologic variability, $\delta^{74} \mathrm{Ge}$ of the Californian and the Peruvian streams can be fit separately against $\mathrm{Ge} / \mathrm{Na}$ or $\mathrm{Ge} / \Sigma^{+}$(where $\Sigma^{+}$is the sum of major cations), which yield similar $\Delta_{\text {solid-liquid }}$ between -1.1 and -0.8\% (Fig. 4).

Pokrovsky et al. (2014) have conducted laboratory experiments showing that Ge removal from solution during Fe-(oxy)hydroxide precipitation results in preferential incorporation of light $\mathrm{Ge}$ isotopes, with fractionation factors $\Delta^{74} \mathrm{Ge}_{\text {solid-liquid }}$ between $-1.7 \%$ (for adsorption) and $-4.4 \%$ (for co-precipitation). Ge incorporation into the mineral lattice often results in a change in Ge coordination with longer and weaker bonds compared to those in dissolved germanic acid (Pokrovsky et al., 2006). At equilibrium, these weaker mineral bonds should preferentially incorporate light Ge isotopes ( $\mathrm{Li}$ et al., 2009; $\mathrm{Li}$ and Liu, 2010), resulting in isotopic fractionation that is consistent with the riverine $\delta^{74} \mathrm{Ge}$ signatures presented here.

\subsubsection{Fractionation during biological uptake}

Biological uptake of Ge by vegetation and freshwater diatoms may potentially exhibit additional control on riverine $\delta^{74} \mathrm{Ge}$ composition. Plants are known to discriminate against Ge during nutrient uptake, in some cases raising Ge/Si of the soil pore water (e.g., Derry et al., 2005; Lugolobi et al., 2010; Meek et al., 2016). However, this process can only have a limited effect due to low Ge uptake rates (Blecker et al., 2007; Delvigne et al., 2009). In addition, bulk river chemistry can only be affected transiently with changing vegetation biomass, typically only over seasonal timescales. Finally, any fractionation by vegetation would likely result in a positive $\delta^{74} \mathrm{Ge} v \mathrm{vs}$. Ge/Si, in contrast 
to the negative relationship observed (Fig. 1b). It may be responsible for some of the scatter observed but it does not appear to be a major driver of Ge chemistry in the watersheds investigated here.

Marine diatoms are also known to discriminate against $\mathrm{Ge}$, but only when stressed for $\mathrm{Si}$ (Sutton et al., 2010). The Lower Kern river is strongly affected by diatom growth in a dam reservoir upstream of the sampling point (Table 1). Mass balance calculations show that up to $89 \% \mathrm{Si}$ and $44 \%$ Ge has been removed by diatom growth in the reservoir (Supp. Table S3). While Ge/Si has been strongly fractionated, $\delta^{74} \mathrm{Ge}$ composition remains unchanged within analytical uncertainty relative to that expected from conservative mixing of the feeding rivers. This provides evidence against significant $\delta^{74} \mathrm{Ge}$ fractionation by freshwater diatoms, consistent with findings in the marine environment (see Section 4.2). The data presented here therefore suggests that riverine $\delta^{74} \mathrm{Ge}$ is primarily controlled by weathering reactions.

\subsubsection{Comparison to other isotopic weathering proxies}

Considering all of the above, riverine $\delta^{74} \mathrm{Ge}$ appears to be a promising weathering tracer that could complement already established proxies, such as $\delta^{30} \mathrm{Si}$ and $\delta^{7} \mathrm{Li}$. The sense of fractionation, where the dissolved phase is heavy and secondary minerals are light, is in agreement with $\delta^{30} \mathrm{Si}$ (e.g., De La Rocha et al. (2000); Georg et al. (2007); Hughes et al. (2013)). However, whereas $\delta^{30} \mathrm{Si}$ can be significantly affected by vegetation cycling (eg., Ziegler et al. (2005); Opfergelt et al. (2006); Cornelis et al. (2010)), as we argue above, $\delta^{74} \mathrm{Ge}$ is unlikely to be strongly influenced by this process. If true, $\delta^{74} \mathrm{Ge}$ could be a powerful tool to disentangle the biological influence on the riverine $\mathrm{Ge} / \mathrm{Si}$ and $\delta^{30} \mathrm{Si}$ signatures.

$\delta^{74} \mathrm{Ge}$ could also provide a useful complement to $\delta^{7} \mathrm{Li}$, which is fractionated in the same direction during secondary clay precipitation (e.g., Huh et al. (2001); Bagard et al. (2015); Pogge von Strandmann and Henderson (2015)). However, Ge is typically incorporated into both tetrahedral and octahedral sites in secondary minerals (Bernstein, 1985; Pokrovsky et al., 2006), whereas Li typically enters octahedral and interlayer cation sites (Vigier et al., 2008; Wimpenny et al., 2015), 
often replacing Mg (Wimpenny et al., 2010; Pogge von Strandmann et al., 2012). The careful investigation of $\delta^{74} \mathrm{Ge}$ and $\delta^{7} \mathrm{Li}$ together could therefore help disentangle different secondary weathering reactions and their spatial variability on the soil or the catchment scale.

\subsubsection{Anthropogenic influence and the global riverine $\delta^{74} \mathrm{Ge}$ signature}

Qi et al. (2011) have demonstrated that Ge-rich coals in the Lincang deposit in China are isotopically variable, with $\delta^{74} \mathrm{Ge}$ ranging from -2.59 to $4.72 \%$ and ash produced during coal combustion further enriched in light isotopes by up to $2.25 \%$. As a result, care needs to be exercised when trying to assess the natural riverine $\delta^{74} \mathrm{Ge}$ composition in areas with known coal deposits and coal power generation. It has been shown that several of the world's major rivers, including the Mississippi, are enriched in Ge due to coal ash contamination (Mortlock and Froelich, 1987; Froelich and Lesley, 2001), which can explain why the Mississippi does not fit the fractionation pattern observed in the rest of the rivers (Fig. 4). The other rivers presented here are most likely free of coal ash contamination, with the possible exception of the Lower Kern, where a coal power plant is present about $60 \mathrm{~km}$ downstream of the sampling point.

Although the dataset presented here lacks many of the world's major rivers, it can be used to determine a preliminary value for the global $\delta^{74} \mathrm{Ge}_{\text {riv }}$ signature. Using the relationship in Fig. 1a and the average (uncontaminated) riverine Ge concentration of $\sim 100 \mathrm{pM}$ based on the global compilation of Froelich et al. (1992) yields a global $\delta^{74} \mathrm{Ge}_{\text {riv }}$ of $\sim 4.5 \%$. This estimate, however, does not account for the non-linear averaging effect, which should result in a lower global $\delta^{74} \mathrm{Ge}_{\text {riv }}$ estimate, due to the negative correlation between Ge concentration and $\delta^{74} \mathrm{Ge}$ composition of individual rivers (Fig. 1a). Additionally, a true global mean value would have to be discharge weighted. In the dataset presented here, the Mississippi river has an annual discharge of about $580 \mathrm{~km}^{3} / \mathrm{y}$, while the next largest river in our data set - Madre de Dios - is about ten times smaller $\left(50 \mathrm{~km}^{3} / \mathrm{y}\right)$. The rest of the rivers in Table 1 are much smaller still, which means that weighing the current dataset by discharge would result in a mean estimate that is heavily dominated by the anthropogenically contaminated Mississippi. Considering all of this, we select a 
very preliminary global mean value of $3.5 \pm 1.5 \%$ since the true value could lie anywhere in the 2-5 \%o range. Analysis of the world's major rivers, especially those unlikely to be contaminated by coal combustion, such as the Amazon, is needed to obtain a more robust estimate.

Finally, the potential alteration of the riverine $\delta^{74} \mathrm{Ge}$ signature during estuarine processes is currently unknown. A previous study has shown that some Ge may be released from the riverine suspended load upon mixing with seawater (Froelich et al., 1985b) and this source is taken into account in the global budget presented below (see Section 4.4). In addition, non-conservative loss of $\mathrm{Ge}$ due to organic matter flocculation, although not observed to date, is theoretically possible and should be addressed in future studies.

\subsection{Seawater}

The seawater $\delta^{74} \mathrm{Ge}$ composition is about $2.6 \%$ higher than the continental or oceanic crust (Table 2, Fig. 2). This observation is not surprising, given a blend of hydrothermal and weathering inputs that are both enriched in heavy Ge isotopes (see Sections 3.1 and 3.3). However, seawater has to reflect the isotopic composition of both sources and sinks, which is discussed in Section 4.4.

The deep water ${ }^{74} \mathrm{Ge}_{\mathrm{sw}}$ in all three basins is identical within uncertainty (Fig. 2). Differences might be expected based on the relatively short (3-6 ky) residence time of Ge in the ocean (see Section 4.4) but are below the level of precision obtained here. There is one exception - bottom seawater and core incubations at one continental shelf site in the Gulf of Mexico are $~ 1 \%$ lighter than the rest of the seawater samples. These samples most likely reflect the strong influence of the Mississippi River, which has a very similar $\delta^{74} \mathrm{Ge}$ signature (Table 1), since they are situated within $100 \mathrm{~km}$ of the river delta and within the river plume (Baronas et al., 2016). Alternatively, these lower $\delta^{74} \mathrm{Ge}$ values may partially reflect the dissolution of terrigenous particles delivered by the Mississippi or previously formed authigenic (and isotopically fractionated, see Section 4.4) phases. One possible scenario is that seasonal hypoxia had caused shoaling of the pore water Fe redox boundary, resulting in the release of reduced $\mathrm{Fe}$, along with isotopically light $\mathrm{Ge}$ that had previously been adsorbed on Fe oxides. 
The surface seawater at the Gulf of Mexico exhibits elevated Ge/Si ratios (Table 2), due to either biological fractionation by diatoms or the influence of the Mississippi river (Baronas et al., 2016). In the latter case, these waters would be expected to have lower $\delta^{74} \mathrm{Ge}_{\mathrm{sw}}$ (Fig. 2), whereas the observed values are identical within uncertainty to the deep ocean composition. Our preferred interpretation is therefore that surface $\mathrm{Ge} / \mathrm{Si}_{\mathrm{sw}}$ is fractionated during diatom uptake, which implies that this process does not result in significant $\delta^{74} \mathrm{Ge}$ fractionation. This hypothesis is supported by the results of Mantoura (2006), who showed no detectable diatom $\delta^{74} \mathrm{Ge}$ fractionation during diatom culture experiments in Ge-enriched seawater,

\subsection{Hydrothermal fluids}

\subsubsection{High temperature systems}

In high temperature hydrothermal systems, the silica chemistry is primarily controlled by equilibration of fluid with quartz (e.g., Mottl and Holland, 1978; Von Damm et al., 1991). Experimental data have shown that elevated hydrothermal fluid $\mathrm{Ge} / \mathrm{Si}$ could therefore result from thermodynamic differences between $\mathrm{Ge}(\mathrm{OH})_{4(\mathrm{aq})}$ and $\mathrm{Si}(\mathrm{OH})_{4(\mathrm{aq})}$ species and preferential solubilization of $\mathrm{Ge}$ relative to Si during water-rock reactions at high temperature (Pokrovski and Schott, 1998; Evans and Derry, 2002; Pokrovski et al., 2005). Using this framework and measured $\mathrm{Ge} / \mathrm{Si}_{\text {fluid }}$ and $\delta^{74} \mathrm{Ge}_{\text {fluid }}$ values in hydrothermal discharge from the East Pacific Rise $\left(340-380{ }^{\circ} \mathrm{C}\right.$ fluids) and Loihi seamount (21-54 ${ }^{\circ} \mathrm{C}$ fluids), Escoube et al. (2015) obtained an average $\delta^{74} \mathrm{Ge}_{\text {quartz }}$ of $\sim-2.4$ $\%$ and equilibrium fractionation factor $\Delta^{74} \mathrm{Ge}_{\text {quartz-fluid }}$ of $\sim-4.1 \%$ (ranging between -0.3 and $-7.7 \%)$ at these sites.

Applying this model to the Middle Valley fluids analyzed in this study, we obtain $\delta^{74} \mathrm{Ge}_{\text {quartz }}$ of $-3.0 \pm 0.3$ and $\Delta^{74} \mathrm{Ge}_{\text {quartz-fluid }}$ of $-4.5 \pm 0.4 \%$, in good agreement with Escoube et al. (2015). Middle Valley fluids interact with a thick (up to $2 \mathrm{~km}$ ) sediment blanket before discharging, which can affect the fluid chemistry. For example, alkali metals and calcium are especially affected, although water-rock interaction in the high-temperature reaction zone is still the dominant process setting the fluid chemistry, as indicated by conservative Si concentrations and ${ }^{87} \mathrm{Sr} /{ }^{86} \mathrm{Sr}$ ratios 
(Butterfield et al., 1994). The good agreement between the Middle Valley fluids and other high temperature systems investigated by Escoube et al. (2015) indicates that in this and perhaps other sedimented hydrothermal systems $\delta^{74} \mathrm{Ge}_{\text {fluid }}$ is not strongly affected by fluid interaction with the overlying sediment.

In contrast, applying the quartz equilibrium model of Escoube et al. (2015) to the Loihi fluids presented here yields $\delta^{74} \mathrm{Ge}_{\text {quartz }}$ between -0.4 and $0.1 \%$ and $\Delta^{74} \mathrm{Ge}_{\text {quartz-fluid }}$ between -1.2 and $-0.6 \%$, significantly smaller than the values obtained in the previous study. The Loihi samples presented here were collected as high-temperature $\left(\sim 200^{\circ} \mathrm{C}\right)$ jet fluids that were observed and sampled only in October 1996, a few months after an explosive eruption of the seamount. By 2006-2007, the system had returned to a "steady state" venting of diffuse, low temperature (20-60 ${ }^{\circ} \mathrm{C}$ ) fluids (Glazer and Rouxel, 2009), which were sampled and analyzed by Escoube et al. (2015). The simplest explanation for the discrepancy between our $\delta^{74} \mathrm{Ge}_{\text {fluid }}$ data and that of Escoube et al. (2015) is therefore a decrease in water-rock interaction temperature from 1996 to 2006, which would result in an increase of the $\Delta^{74} \mathrm{Ge}_{\text {quartz-fluid }}$ magnitude over time, as predicted by quantum chemistry calculations (Li et al., 2009).

A change in temperature should also affect the fluid Ge/Si ratio, which appears to have decreased from $49-52 \mu \mathrm{mol} / \mathrm{mol}$ in 1996 (Table 3) to around $30 \mu \mathrm{mol} / \mathrm{mol}$ in 2006-2007 (Escoube et al., 2015). There is a disagreement in the literature on how a decrease in temperature should affect the Ge/Si ratio of equilibrated fluid. Using a hexagonal quartz-like $\mathrm{GeO}_{2}$ structure, Evans and Derry (2002) predicted that $\mathrm{Ge} / \mathrm{Si}$ ratio in fluids should increase with decreasing temperature, consistent with observations at various high temperature systems (Mortlock et al., 1993; Escoube et al., 2015). In contrast, using a tetragonal rutile-like $\mathrm{GeO}_{2}$ structure, Pokrovski et al. (2005) predicted a decrease in $\mathrm{Ge} / \mathrm{Si}$ ratio with decreasing temperature, in agreement with Icelandic and Cascade hydrothermal fluids (Arnorsson, 1984; Siebert et al., 2011).

In addition, $\mathrm{Li}$ et al. (2009) have demonstrated that $\Delta^{74} \mathrm{Ge}_{\text {solid-fluid values for a range of min- }}$ erals are strongly dependent on the length of the Ge-O bond in the mineral structure. Furthermore, they used a tetrahedral $\mathrm{GeO}_{2}$ structure to simulate quartz binding environment, which has Ge-O 
bond length of $1.753 \AA$, similar but slightly shorter than $\mathrm{Ge}(\mathrm{OH})_{4(\mathrm{aq})}(1.77 \AA)$. As a result, the calculations predict a small but positive $\Delta^{74} \mathrm{Ge}_{\text {quartz-fluid }}$ value, ranging from $1.1 \%$ at $25^{\circ} \mathrm{C}$ to 0-0.15\% at $300-400{ }^{\circ} \mathrm{C}$ (the estimated water-rock interaction temperature at Loihi; Sedwick et al. (1992)), in direct disagreement with the field data presented here and by Escoube et al. (2015). The field and theoretical values of $\Delta^{74} \mathrm{Ge}_{\text {quartz-fluid }}$ can be brought in agreement if the mineral $\mathrm{Ge}-\mathrm{O}$ bond length is instead set to $1.88 \AA$, as measured in tetragonal $\mathrm{GeO}_{2}$ (Hazen and Finger, 1981). Using the relationship between $\mathrm{Ge}-\mathrm{O}$ and the reduced isotope partitioning function ratio (RPFR) given by Li et al. (2009), we obtain $\Delta^{74} \mathrm{Ge}_{\text {rutile-fluid }}$ of $-7.2 \%$ at $25{ }^{\circ} \mathrm{C}$. While currently no calculations are available to predict this value for temperatures above $200{ }^{\circ} \mathrm{C}$, it is expected to be much lower, likely in the -1 to $-3 \%$ range, which would be consistent with the field-derived values.

The temporal evolution of Loihi $\delta^{74} \mathrm{Ge}_{\text {fluid }}$ data could also be explained by increasing kinetic isotope effects, due to Rayleigh-type depletion of (preferentially light) Ge in the fluids, and/or larger kinetic fractionation factors associated with the precipitation of amorphous silica or other hydrothermal minerals at lower fluid temperatures. The importance of kinetic fractionation during similar processes has been recently demonstrated for the $\delta^{30} \mathrm{Si}$ system (Oelze et al., 2014; Geilert et al., 2014, 2015).

There are other possible explanations for the evolution of the Loihi fluids from 1996 to 2006, such as an increase in pH-controlled congruency of basalt weathering (Wheat et al., 2000), or perhaps transient dissolution of Ge-enriched and isotopically light deposits (Escoube et al., 2015) in the months after the eruption. A full exploration of these possibilities is outside of the scope of this study, however. In the end, these data demonstrate that there is not a simple relationship between Ge/Si and $\delta^{74} \mathrm{Ge}$ in high temperature fluids and further studies of both the fluids and the solids in diverse hydrothermal systems are needed. 


\subsubsection{Low temperature systems}

Our results show that low-temperature fluids of the Juan de Fuca Ridge (JdFR) exhibit higher $\delta^{74} \mathrm{Ge}_{\text {fluid }}$ relative to high temperature systems (Fig. 3). To some degree, this might be the result of larger equilibrium or kinetic fractionation factors at the lower reaction temperature (Li et al., 2009). The heavy isotopic composition of these fluids would once again require a much larger and negative $\Delta^{74} \mathrm{Ge}_{\text {mineral-fluid }}$ than that predicted by Li et al. (2009) for fluid equilibration with quartz (see the discussion above). However, unlike in high temperature hydrothermal systems, fluids in low temperature systems are unlikely to achieve true chemical equilibrium with most of the mineral phases that they circulate through. Instead, their chemistry is strongly controlled by the degree of crust alteration, that is, the partial dissolution of basalt and the precipitation of various secondary minerals (e.g., Wilkens et al., 1991).

The JdFR flank fluids analyzed had low Mg concentrations, which varied depending on the degree of dilution with seawater during sampling but extrapolate to formation fluids with $\mathrm{Mg}$ concentrations of $1 \mathrm{mmol} / \mathrm{kg}$ for Baby Bare and 2-28 mmol/kg for ODP sites (Wheat et al., 2004; Wheat and McManus, 2005). Mg depletion in hydrothermal fluids is caused by the precipitation of secondary Mg-rich clay minerals during basalt alteration. Since these clays also incorporate Si and $\mathrm{Ge}$, the measured $\mathrm{Mg}$ anomaly can be used to estimate the minimum amount of Si and Ge that had been initially released and then removed during secondary clay precipitation. Wheat and McManus (2008) have calculated these values to be $50-100 \mathrm{mmol} / \mathrm{kg} \mathrm{Si}$ and $120-250 \mathrm{nmol} / \mathrm{kg}$ Ge assuming the precipitation of chlorite/scectite with $\mathrm{Si} / \mathrm{Mg}$ stoichiometry of 2 (Seyfried, 1987). A four times higher estimate is obtained by assuming the precipitation of celadonite with $\mathrm{Si} / \mathrm{Mg}$ stoichiometry of 8 (Wheat and McManus, 2008). Such high concentrations were probably never achieved in the fluids, since both the release of elements from basalt dissolution and the uptake into secondary minerals are likely to take place simultaneously. Considering that Ge concentrations measured in the fluids are $9-22 \mathrm{nmol} / \mathrm{kg}$, this implies that only 1-8 \% of the originally released Ge remains in solution by the time the fluids upwell into the water column (Supp. Table S4; see Supp. text for detailed calculations). 
Assuming that $\mathrm{Ge}$ is leached from basalt without isotopic fractionation, the $\delta^{74} \mathrm{Ge}_{\text {fluid }}$ should then primarily be controlled by the the degree of Ge removal into secondary minerals and the $\Delta^{74} \mathrm{Ge}_{\text {mineral-fluid }}$ associated with this reaction (Fig. 5), similar to the low-temperature weathering reactions (see Section 4.1). This calculation does not require that Ge removal be ascribed to a specific secondary mineral. Although it is highly likely to be the same secondary silicate that removes $\mathrm{Si}$ and $\mathrm{Mg}$, dissolved $\mathrm{Fe}$ is also known to diffuse from the overlying sediments and to precipitate as oxides and sulfides within the basement reaction zone (Wheat et al., 2002), providing an alternative pathway for Ge removal from solution. While there are no $\Delta^{74} \mathrm{Ge}_{\text {mineral-fluid values }}$ yet determined for most typical hydrothermal clays, the values determined for Fe oxides agree well between theoretical and experimental studies (Li and Liu, 2010; Pokrovsky et al., 2014), enabling us to adapt them to different reaction temperatures, and therefore serve as a good starting point.

The isotopic fractionation associated with a reaction involving a phase change can be estimated by assuming either a Batch system, where the two phases are allowed to isotopically equilibrate, or a Rayleigh type system, where they are separated (see Supp. Material for equations). Due to the long (5-10 ky; Elderfield et al. (1999)) residence time of these fluids in the basement, it is possible for either of these two models to be applicable, depending on the secondary minerals involved and the spatial locus of the reactions involving Ge.

Fig. 5 shows that the measured JdFR flank $\delta^{74} \mathrm{Ge}_{\text {fluid }}$ composition agrees well with the values predicted by the Ge depletion model, considering the uncertainties and the number of assumptions made. The measured values fall in the middle between those predicted by the Batch and the Rayleigh variants of the model. While these calculations were done assuming no isotopic fractionation during the initial basalt dissolution, the model is relatively insensitive to this assumption and is primarily governed by the fractionation factor associated with the secondary mineral precipitation. For example, even if the starting "basalt" isotopic composition is offset by $2 \%$ in either direction, the data is still fit well with at least one of the model scenarios shown in Fig. 5. 


\subsection{Global budget}

The major sources of Ge to the ocean are rivers and hydrothermal fluids, and the main sinks are the burial of opal (bSi) and non-opal authigenic minerals in marine sediments (Table 4, Fig. 6). The first attempt to constrain the global Ge isotope budget was by Escoube et al. (2015). By assuming a riverine and seawater $\delta^{74} \mathrm{Ge}$ composition of $3.0 \%$ (quite close to the actual values, as determined in this study), they estimated a fractionation of about $2 \%$, associated with Ge removal into authigenic marine phases (the non-opal sink). Here, we provide an updated global $\delta^{74} \mathrm{Ge}$ budget, utilizing data-based estimates of the riverine and seawater isotopic composition as given above and a more thorough treatment of the less well constrained fluxes (Table 4).

A number of assumptions had to be made for the fluxes where little to no data exist. For example, we estimated a groundwater $\delta^{74} \mathrm{Ge}$ signature assuming that the riverine $\delta^{74} \mathrm{Ge}$ vs. Ge/Si applies to these fluids as well, since their composition is largely controlled by the same set of weathering reactions. In contrast to previous Ge budget estimates (e.g., King et al., 2000; Hammond et al., 2004b; Escoube et al., 2015), we have also assumed that there is no Ge/Si (and by extension no $\delta^{74} \mathrm{Ge}$ ) fractionation associated with the dissolution of aeolian dust and riverine detrital material in seawater, as secondary mineral formation is unlikely to happen in the water column and any such process within the pore waters is accounted for by the non-opal flux. Due to the relatively small detrital Ge input, this latter assumption does not strongly influence the overall global budget or the model results discussed below, as confirmed by sensitivity tests. Finally, we treat low temperature hydrothermal fluids without separating the effect of the "warm" ( $>10^{\circ} \mathrm{C}$ ) fluids from the basalt alteration (sometimes termed the low-temperature basalt weathering) associated with "cool" (<10 ${ }^{\circ} \mathrm{C}$ ) fluids but allow for a large $\mathrm{Ge} / \mathrm{Si}$ uncertainty due to poor constraints on the latter process (Wheat and McManus, 2008). These and other assumptions, along with the literature data sources, are listed in the footnotes of Table 4.

In the end, the two least well constrained fluxes in the Ge cycle are the ridge-flank (low temperature) hydrothermal input and the non-opal burial output (Table 4). While the Si flux associated with low-temperature $\left(<63^{\circ} \mathrm{C}\right)$ alteration of oceanic crust is estimated to be low (Wheat 
and McManus, 2005; Tréguer and De La Rocha, 2013), the wide range of Ge/Si values observed in low-temperature hydrothermal fluids results in a high uncertainty of the Ge flux associated with this process. However, the constraints on the non-opal Ge burial flux are arguably poorer still (Hammond et al., 2000; McManus et al., 2003; Baronas et al., 2016) and there are currently no published data regarding its $\delta^{74} \mathrm{Ge}$ composition. Assuming a steady state in the global ocean Ge cycle, inputs must balance outputs:

$$
\Sigma\left(\mathrm{F}_{\text {input }} \times \delta^{74} \mathrm{Ge}_{\text {input }}\right)=\Sigma\left(\mathrm{F}_{\text {output }} \times \delta^{74} \mathrm{Ge}_{\text {output }}\right)
$$

where $\mathrm{F}$ represents the flux of Ge into or out of the ocean, as shown in Table 4. A version of this equation with the expanded formulation of all the individual terms is presented in the Supp. Material (Eq. S8). The steady state assumption is reasonable given the relatively short residence time of Ge in the ocean (see discussion below). However, it can only truly be tested once more accurate estimates are obtained for all the fluxes in the marine Ge cycle.

Using Eq. 2 we can estimate the flux and the $\delta^{74} \mathrm{Ge}$ composition of the non-opal Ge burial flux. This calculation was done 100,000 times, each time randomly selecting a value of each parameter in Table 4 from within its associated uncertainty (i.e., the Monte Carlo approach). Additional details of the model used are given in the Supp. Material. The median non-opal Ge burial flux value is calculated as $13.4 \pm 10.7 \mathrm{Mmol} / \mathrm{y}$. Although this range encompasses previous estimates, the median value is 2-3 times larger compared to previous budgets, which typically did not include a number of the secondary Ge fluxes, such as groundwater or suspended river load inputs (Hammond et al., 2000; King et al., 2000; Escoube et al., 2015) and which did not account for the possibility of significant Ge inputs during basalt alteration at temperatures at or below $20{ }^{\circ} \mathrm{C}$ (Wheat and McManus (2005); but see also Wheat and McManus (2008)). This new larger estimate, however, is in agreement with the recent value of $18 \pm 14 \mathrm{Mmol} / \mathrm{y}$ that was calculated based on field measurements of Ge non-opal burial in marine sediments around the globe (Baronas et al., 2016).

Using Eq. 2, the Ge isotope composition associated with non-opal burial was calculated to be 2.7 
$\pm 1.7 \%$, or about $0.5 \%$ lower than seawater (Table 4 ), indicating possible preferential incorporation of light $\mathrm{Ge}$ isotopes into authigenic marine phases, most likely Fe oxides or aluminosilicate clays (Baronas et al., 2016). This implied fractionation is lower but within uncertainty of the $-2 \%$ previously estimated by Escoube et al. (2015) and also similar to the $\Delta^{74} \mathrm{Ge}_{\text {mineral-fluid }}$ calculated from riverine composition (Fig. 4) and Fe oxide precipitation experiments (Pokrovsky et al., 2014). Studies of marine sediments and pore waters affected by this process are needed to confirm this value and further put better constraints on the Ge isotope budget.

Another caveat of the current marine $\mathrm{Si}$ and Ge budget is the highly uncertain flux of sponge $\mathrm{bSi}$ burial. The relatively large value used here (Table 4) was first proposed by Tréguer and De La Rocha (2013) to close the modern Si budget, despite the lack of direct evidence for such large significance of sponges globally. It is possible that Si burial during reverse weathering (i.e., clay authigenesis, which may also be driving non-opal Ge burial) is instead more important than previously thought (e.g., Michalopoulos and Aller, 2004), as demonstrated by a recent study utilizing cosmogenic ${ }^{32} \mathrm{Si}$ (Rahman et al., 2016). In this case, a lower sponge Si burial flux would be needed to balance the Si budget, resulting in a lower Ge sponge burial flux, and therefore requiring a lighter $\delta^{74} \mathrm{Ge}_{\text {non-opal }}$ value to balance the modern Ge isotope budget. This would imply a larger $\Delta^{74} \mathrm{Ge}_{\text {mineral-fluid }}$ associated with marine sediment authigenesis.

Finally, the Ge mass budget presented here (Table 4) can be used to update the estimate of the residence time of the inorganic Ge species in the ocean. Using the global ocean Si inventory of 97,000 Tmol (Tréguer and De La Rocha, 2013), and Ge/Si of $0.76 \mu \mathrm{mol} / \mathrm{mol}$ (Froelich et al., 1985a; Sutton et al., 2010), yields a Ge inventory of 73,700 Mmol. Depending on which set of fluxes is used, Ge residence time in the oceans is calculated as $4300 \pm 1500$ (median \pm 1 S.D.). These values are shorter than previous estimates of $\sim 10,000$ y (Hammond et al., 2000), due to the recognition of likely additional Ge sources to the ocean (see discussion above). A similar correction was recently calculated for the Si cycle, resulting in a residence time that has been revised from $\sim 15,000-20,000$ y (Treguer et al., 1995) to 10,000 - 12,000 y (Tréguer and De La Rocha, 2013; Frings et al., 2016). The global Ge isotope budget presented here sets up a basic framework for a possible inter- 
pretation of future $\delta^{74} \mathrm{Ge}_{\mathrm{sw}}$ records. The one pore water $\delta^{74} \mathrm{Ge}$ measurement was identical to seawater (Table 2, Fig. 2), suggesting that there is little if any $\delta^{74} \mathrm{Ge}$ fractionation associated with bSi dissolution and early diagenesis in the sediments. Combined with the lack of observed biological fractionation by diatoms (see Section 4.1), diatom $\delta^{74} \mathrm{Ge}$ promises to be a powerful proxy for tracing secular changes in the isotopic composition of the seawater. When combined with the available $\mathrm{Ge} / \mathrm{Si}_{\mathrm{Sw}}$ records (Shemesh et al., 1989; Mortlock et al., 1991), it is bound to yield new insights into past continental silicate weathering and/or cycling of biogenic silica in the ocean.

\section{Conclusions}

We present measurements of Ge isotopic composition $\left(\delta^{74} \mathrm{Ge}\right)$ in seawater, several rivers, and low and high temperature hydrothermal fluids. All these fluids are significantly fractionated towards heavy $\delta^{74} \mathrm{Ge}$ composition relative to silicate rocks from which Ge is leached, most likely due to the precipitation of secondary phases that are isotopically light. River waters show the highest variability, spanning a $\sim 4 \%$ range of $\delta^{74}$ Ge values. The deep ocean, on the other hand, appears to be mostly homogeneous within the uncertainty of our measurements. High temperature hydrothermal system fluids are less fractionated than low-temperature ones. It therefore appears that the reaction zone temperature and the degree of Ge removal from solution into hydrothermal minerals could be the main controls of $\delta^{74} \mathrm{Ge}$ in hydrothermal fluids.

The data presented here, along with that published previously, characterizes the $\delta^{74} \mathrm{Ge}$ composition of all the major oceanic Ge sinks and sources, except for non-opal burial (i.e., authigenesis in marine sediments). Assuming that the contemporary Ge cycle is at steady state, we have calculated that there should be an isotopic fractionation of $-0.6 \pm 1.8 \%$ (solid-solution) associated with non-opal Ge burial in marine sediments. The large uncertainty (including the sign) of this value is primarily due to poor constraints on Ge input from ridge-flank hydrothermal fluids. A better estimate of this value (ideally from direct measurements) is needed to assess the sensitivity of $\delta^{74} \mathrm{Ge}_{\mathrm{sw}}$ to this process and therefore its potential to trace input (weathering vs. hydrothermal) 
or output (opal vs. non-opal burial) dynamics in the past.

Despite the large remaining uncertainties, this study marks an important early step towards applying $\delta^{74} \mathrm{Ge}$ as a paleoceanographic proxy. Considering the short residence time of Ge in the ocean (4300 $\pm 1500 \mathrm{yr}$, based on our budget), paleorecords of $\delta^{74} \mathrm{Ge}_{\mathrm{sw}}$ may help test important hypotheses on the causes and consequences of glacial-interglacial cycles, such as changes in rates of silicate weathering (e.g., Vance et al., 2009; von Blanckenburg et al., 2015) and volcanic degassing (e.g., Lund et al., 2016; Huybers and Langmuir, 2017), as well as the causes of cooling over the Cenozoic, which may have been driven by short-term bursts of silicate weathering (Caves et al., 2016) that may be undetectable by proxies with long oceanic residence times.

\section{Acknowledgments}

This study was funded by National Science Foundation grant OCE-1061700 to DEH. Some of the hydrothermal sample analyses were supported by NSF grants OCE-0327016 and OCE-0326574 to JM, and CS was also supported in part by Swiss NSF grant PBBE2-102997 and ACS PRF\# 40264-AC2.

We appreciate the assistance of a number of colleagues in sample collection: Ed Boyle collected and filtered the Atlantic Water on the Geotraces Intercalibration cruise, and Tabitha Esther and Rick Schwartz assisted with collection of the Pacific samples and early protocol development. Peruvian river samples were collected by Mark Torres, A. Joshua West, Camilo Ponton, and Adan Ccahuana. Other river water samples were obtained with assistance from Paulina Pinedo, Harris Talsky, Gina Erazo, Jane Hammond, Doug Barna, and Rick Schwartz. Gulf of Mexico samples were collected during R/V Endeavor cruise EN-497 with the help from William Berelson, Silke Severmann, Nick Rollins, Jesse Muratli, April Abbott, Joe Jennings, and Kanchan Maiti. Olivier Rouxel has provided valuable discussion, advice, and an initial aliquot of what is now the NIST 3120a standard. Jim Moffett and Sergio Sañudo-Wilhelmy have allowed us to use their ICP-MS, and A. Joshua West his MP-AES. Andy Ross, Andy Ungerer and Brian Haley have assisted with the work at OSU. 

reviewers have greatly improved this manuscript. We thank Horst Marschall for editorial handling. ${ }_{654}$ Gen Li and Mark Torres are thanked for fruitful discussions prior to submission. 
Table 1: Summary of measured riverine $\delta^{74} \mathrm{Ge}$ and sample details. Asterisk indicates possible anthropogenic influence.

\begin{tabular}{|c|c|c|c|c|c|c|c|}
\hline Sample & Lat., ${ }^{\circ}$ & Long., ${ }^{\circ}$ & Lithology $^{a}$ & {$[\mathbf{G e}], \mathbf{p M}$} & {$[\mathbf{S i}], \mu \mathbf{M}$} & $\begin{array}{l}\mathrm{Ge} / \mathrm{Si} \text {, } \\
\mu \mathrm{mol} / \mathrm{mol}\end{array}$ & $\delta^{74} \mathrm{Ge}, \% 0^{b}$ \\
\hline \multicolumn{8}{|l|}{ California } \\
\hline Kern River (North fork) & 35.8 & -118.4 & $\mathrm{gr}$ & 614 & 327 & 1.88 & 2.75 \\
\hline Kern River (South fork) & 35.8 & -118.2 & $\operatorname{mixed}^{c}$ & 97 & 361 & 0.27 & 5.37 \\
\hline Kern River (Lower)* $d$ & 35.6 & -118.5 & $\operatorname{mixed}^{e}$ & 299 & 36 & 8.28 & 3.04 \\
\hline San Gabriel River (North fork) & 34.3 & -117.7 & $\mathrm{gr}$ & 68 & 256 & 0.26 & 5.61 \\
\hline San Gabriel River (West fork) & 34.3 & -117.7 & $\mathrm{gr}$ & 81 & 331 & 0.24 & 4.67 \\
\hline San Gabriel River (Lower) $* f$ & 33.8 & -118.1 & $\mathrm{gr}$ & 422 & 230 & 1.84 & 3.91 \\
\hline Hondo River & 34.1 & -118.0 & $\mathrm{gr}$ & 172 & 290 & 0.59 & 5.50 \\
\hline \multicolumn{8}{|l|}{ Andes-Amazon (Peru) } \\
\hline Kosnipata Stream (MMD-02) $g$ & -13.06 & -71.54 & sh & 90 & 236 & 0.38 & 4.96 \\
\hline Carbon Stream (MMD-06) ${ }^{g}$ & -12.89 & -71.36 & $\mathrm{sh}+\mathrm{gr}$ & 258 & 188 & 1.37 & 3.30 \\
\hline Madre de Dios River (MMD-28) $h$ & -12.58 & -70.10 & $\mathrm{sh}+\mathrm{gr}$ & 107 & 128 & 0.84 & 3.24 \\
\hline Inambari River (MMD-29) ${ }^{h}$ & -12.72 & -69.75 & $\mathrm{sh}+\mathrm{gr}$ & 211 & 160 & 1.32 & 3.17 \\
\hline Madre de Dios River (MMD-32) $h$ & -12.56 & -69.18 & $\mathrm{sh}+\mathrm{gr}$ & 147 & 163 & 0.90 & 3.72 \\
\hline Piedras River (MMD-34) ${ }^{i}$ & -12.52 & -69.25 & $\operatorname{mixed}^{j}$ & 113 & 393 & 0.29 & 4.72 \\
\hline \multicolumn{8}{|l|}{ Hawai'i } \\
\hline Molokai Spring & 21.2 & -157.0 & bas & 809 & 823 & 0.98 & 2.33 \\
\hline Iao Valley River & 20.9 & -156.6 & bas & 120 & 354 & 0.34 & 3.63 \\
\hline \multicolumn{8}{|l|}{ Other } \\
\hline Mississippi River* $k$ & 29.95 & -90.06 & $\operatorname{mixed}^{l}$ & 266 & 166 & 1.60 & 2.01 \\
\hline
\end{tabular}

${ }^{a}$ sh $=$ shale $;$ gr $=$ granitic $;$ bas $=$ basaltic.

${ }^{b} \mathrm{n}=1$ for all samples, external 2 S.D. error $\pm 0.22 \%$.

$c$ Shale, siltstone and sandstone with some granitic outcrops (Bartow and Pittman, 1983).

${ }^{d}$ Sampled downstream of a reservoir, Ge/Si very likely affected by diatom growth.

$e$ Downstream of North and South fork confluence.

$f$ Affected by urban runoff.

$g$ Small Andean catchment.

$h$ Large catchment integrating a large range of elevations from Andes to Amazon foreland floodplain.

$i$ Amazon foreland floodplain river, headwaters draining actively uplifted area.

$j$ Primarily Quaternary with some Miocene deposits.

${ }^{k}$ Affected by urban runoff and coal power plant waste effluents (Froelich and Lesley, 2001).

$l$ A large variety of siliclastic and carbonate sedimentary deposits of various ages (Tom McGlothlin, 1944). 
Table 2: Summary of measured seawater $\delta^{74} \mathrm{Ge}$ and sample details.

\begin{tabular}{|c|c|c|c|c|c|c|c|c|c|}
\hline Sample & Station & $\mathbf{n}=$ & Lat., ${ }^{\circ}$ & Long., ${ }^{\circ}$ & Depth, m & [Ge], pM & {$[\mathbf{S i}], \mu \mathbf{M}$} & $\mathrm{Ge} / \mathrm{Si}, \mu \mathrm{mol} / \mathrm{mol}$ & $\delta^{74} \mathrm{Ge}, \%{ }^{a}$ \\
\hline \multicolumn{10}{|l|}{ PACIFIC OCEAN } \\
\hline Cascadia Basin & $56-2$ & 3 & 48.42 & -127.50 & 2590 & 134 & 182 & 0.74 & $3.40 \pm 0.27$ \\
\hline San Pedro Basin & SPOT & 3 & 33.55 & -118.40 & 500 & 55 & 74 & 0.74 & $3.48 \pm 0.35$ \\
\hline \multicolumn{10}{|l|}{ ATLANTIC OCEAN } \\
\hline Geotraces (GDI-30,31) & BATS & 1 & 31.67 & -64.17 & 2000 & 24 & 17 & 1.36 & $3.46 \pm 0.22$ \\
\hline Geotraces (\#2672) & BATS & 1 & 31.67 & -64.17 & 3500 & 27 & 28 & 0.97 & $3.03 \pm 0.50$ \\
\hline \multicolumn{10}{|l|}{ GULF OF MEXICO } \\
\hline \multicolumn{10}{|l|}{ Deep offshore } \\
\hline CTD-33-1 & Sta. G & 1 & 26.28 & -92.02 & 749.5 & 22 & 25 & 0.86 & $2.63 \pm 0.22$ \\
\hline CTD-32-3 & Sta. G & 1 & 26.28 & -92.02 & 2120.6 & 17 & 25 & 0.70 & $3.07 \pm 0.22$ \\
\hline \multicolumn{10}{|l|}{ Shelf surface } \\
\hline CTD-45-7 & Sta. 9 & 1 & 28.97 & -90.40 & 2 & 43 & 10 & 4.28 & $2.79 \pm 0.50$ \\
\hline CTD-45-8 & Sta. 9 & 2 & 28.97 & -90.40 & 3 & 21 & 9 & 2.20 & $3.23 \pm 0.20$ \\
\hline \multicolumn{10}{|l|}{ Shelf bottom } \\
\hline CTD-6 & Sta. 1 & 2 & 28.59 & -90.54 & 30 & 45 & 25 & 1.84 & $2.21 \pm 0.37$ \\
\hline \multicolumn{10}{|l|}{ Core incubations } \\
\hline MC-2 Core A & Sta. 1 & 1 & 28.59 & -90.54 & 30 & 111 & 70 & 1.59 & $2.71 \pm 0.50$ \\
\hline MC-3 Core A & Sta. 1 & 1 & 28.59 & -90.54 & 30 & 113 & 83 & 1.35 & $2.36 \pm 0.50$ \\
\hline MC-3 Core B & Sta. 1 & 1 & 28.59 & -90.54 & 30 & 113 & 89 & 1.27 & $2.18 \pm 0.50$ \\
\hline \multicolumn{10}{|l|}{ Pore waters } \\
\hline MC-13 0-5 cm depth & Sta. 5 & 1 & 28.14 & -92.16 & 90 & 104 & 127 & 0.82 & $3.05 \pm 0.50$ \\
\hline DEEP OCEAN AVER & & & & & & & & & $3.24 \pm 0.44^{b}$ \\
\hline
\end{tabular}

$a$ Uncertainty given as 2 S.D. of standard reproducibility where $\mathrm{n}=1$ and 2 S.D. of sample replicates where $\mathrm{n}>1$.

$b$ Simple average $( \pm 2$ S.D.) of all samples from $\geqslant 2000 \mathrm{~m}$ depth. 
Table 3: Summary of measured hydrothermal fluid $\delta^{74} \mathrm{Ge}$ and sample details.

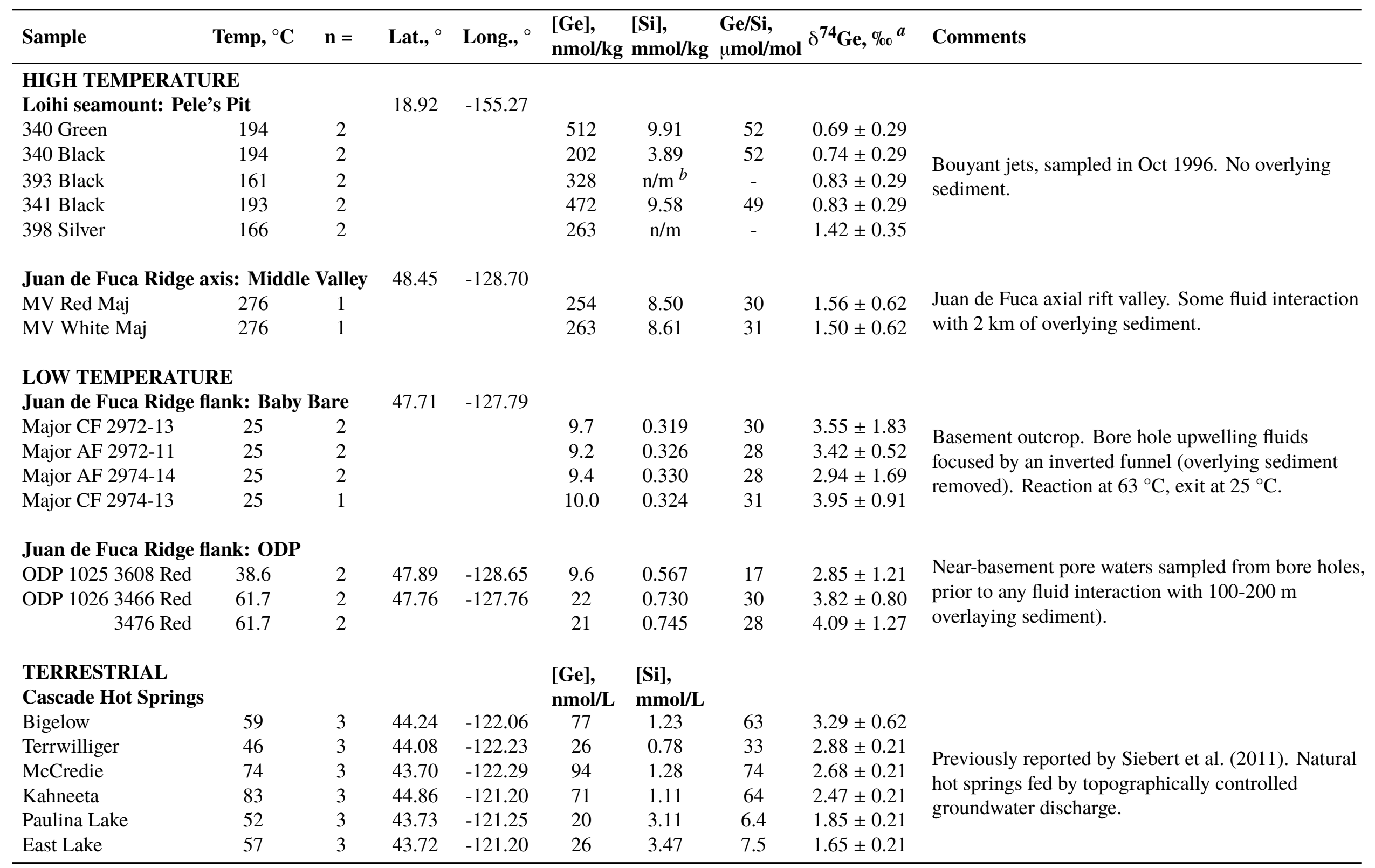

${ }^{a}$ Uncertainty given as 2 S.D. of standard reproducibility where $\mathrm{n}=1$ and 2 S.D. of sample replicates where $\mathrm{n}>1$.

$b$ Not measured. 

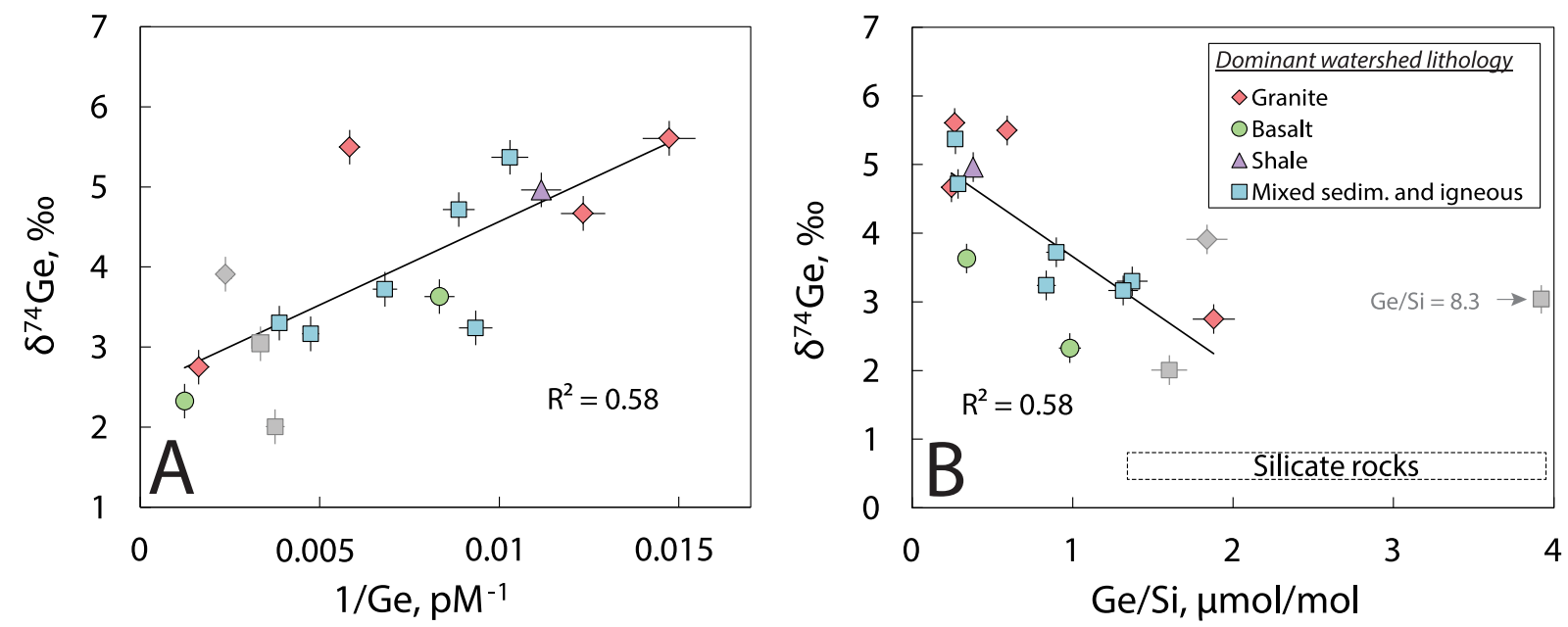

Figure 1: A: Riverine Ge isotope composition as a function of Ge concentration reciprocal. Symbols reflect the dominant lithology of each watershed. Grey symbols are samples affected by anthropogenic activities (Table 1) and are excluded from the linear regression in both panels. B: Riverine Ge isotope composition as a function of Ge/Si. Dashed box shows the range of values observed in mafic, felsic, and sedimentary silicate rocks (Mortlock and Froelich, 1987; Kurtz et al., 2002; Rouxel et al., 2006; Escoube et al., 2012). 
Table 4: Summary of global marine Si and Ge fluxes, along with their estimated $\delta^{74} \mathrm{Ge}$ signatures, assuming steady state.

\begin{tabular}{|c|c|c|c|c|}
\hline Flux & $\begin{array}{c}\text { Si flux }(\mathbf{F S i})^{a}, \\
\text { Tmol } / y\end{array}$ & $\begin{array}{c}\text { Ge/Si, } \\
\mu \mathrm{mol} / \mathrm{mol}\end{array}$ & $\underset{\mathrm{Mmol} / \mathrm{y}}{\mathrm{Ge}} \underset{\mathrm{Mlux}}{(\mathrm{FGe})^{b}}$ & $\begin{array}{c}\delta^{74} \mathbf{G e}, \\
\% 0\end{array}$ \\
\hline \multicolumn{5}{|l|}{ INPUTS } \\
\hline Rivers, dissolved $\mathrm{Si}$ & $5.7 \pm 0.4$ & $0.57 \pm 0.20^{c}$ & $3.2 \pm 1.2$ & $3.5 \pm 1.5^{d}$ \\
\hline Rivers, amorphous $\mathrm{Si}$ & $1.1 \pm 1.0$ & $0.57 \pm 0.30^{e}$ & $0.6 \pm 0.6$ & $3.5 \pm 1.5^{f}$ \\
\hline Groundwater & $0.65 \pm 0.54$ & $0.30 \pm 0.20^{g}$ & $0.2 \pm 0.2$ & $4.5 \pm 1.5^{h}$ \\
\hline Detrital (river susp. load and aeolian) & $1.1 \pm 0.7$ & $1.4 \pm 0.3^{i}$ & $1.6 \pm 1.5$ & $0.56 \pm 0.10^{j}$ \\
\hline Ridge-axis hydrothermal fluids & $0.5 \pm 0.3$ & $9 \pm 6^{k}$ & $4.5 \pm 4.2$ & $1.5 \pm 0.4^{l}$ \\
\hline Ridge-flank hydrothermal fluids & $0.5 \pm 0.4$ & $25 \pm 24^{m}$ & $9.2 \pm 9.2$ & $3.5 \pm 0.5^{n}$ \\
\hline Total & $9.5 \pm 1.4$ & $2.0 \pm 1.1$ & $19.2 \pm 11.2$ & $2.8 \pm 0.7$ \\
\hline \multicolumn{5}{|l|}{ OUTPUTS } \\
\hline Diatom bSi & $6.3 \pm 2.8$ & $0.76 \pm 0.04^{\circ}$ & $5.0 \pm 2.1$ & $3.2 \pm 0.4^{p}$ \\
\hline Sponge bSi & $3.2 \pm 3.2$ & $0.23 \pm 0.12^{q}$ & $0.7 \pm 0.7$ & $2.2 \pm 1.0^{r}$ \\
\hline Non-opal (authigenesis) & - & - & $13.3 \pm 10.6^{s}$ & $2.7 \pm 1.7^{t}$ \\
\hline Total & $9.5 \pm 3.0$ & $2.0 \pm 1.1$ & $19.2 \pm 11.2$ & $2.8 \pm 0.7$ \\
\hline
\end{tabular}

$a$ All Si flux values and uncertainties from Tréguer and De La Rocha (2013); Frings et al. (2016).

$b$ Calculated as $\mathrm{FGe}_{\mathrm{i}}=\mathrm{FSi}_{\mathrm{i}} \times \mathrm{Ge} / \mathrm{Si}_{\mathrm{i}}$, where $i$ is the appropriate subscript, except where noted otherwise.

$c$ Based on global riverine Ge vs. Si slope from Froelich et al. (1992), updated to global average riverine Si concentration from Dürr et al. (2011).

$d$ Estimated using the data presented in this study (see Section 4.1).

$e$ Assumed to be equal to dissolved riverine signature but with a higher uncertainty assigned to account for potential biological fractionation.

$f$ Assumed equal to riverine composition, based on the lack of evidence for biological $\delta^{74} \mathrm{Ge}$ fractionation (see Sections 4.1 and 4.2).

$g$ Based on data from Kurtz et al. (2011).

$h$ Based on the $\delta^{74} \mathrm{Ge}$ vs. Ge/Si relationship in Fig. 1.

$i$ Assumed congruent weathering: equal to average continental crust (Froelich et al., 1992).

$j$ Assumed congruent weathering: equal to average continental crust (Escoube et al., 2012).

$k$ Mortlock et al. (1993); Wheat and McManus (2005).

$l$ Average of axial fluids from EPR (Escoube et al., 2015) and JdFR (this study). This value is identical to the previous estimate of Escoube et al. (2015).

${ }^{m}$ Warm $\left(10-60{ }^{\circ} \mathrm{C}\right)$ fluids typically have avg. $\mathrm{Ge} / \mathrm{Si}$ of $25 \mu \mathrm{mol} / \mathrm{mol}$, whereas the effect of basalt alteration at $<10{ }^{\circ} \mathrm{C}$ is very poorly constrained, and may be dominated by marine porewater signature of $\sim 1 \mu \mathrm{mol} / \mathrm{mol}$ (Wheat and McManus, 2005). We therefore assign a large uncertainty, encompassing a range of possible fluid Ge/Si signatures.

$n$ Average of ridge flank fluids (Baby Bare and ODP data presented here).

$o$ Froelich et al. (1985a); Sutton et al. (2010)

$p$ Assumed to be equal to average seawater reported in this study (Table 2, Fig. 2).

$q$ Ellwood et al. (2006)

$r$ Rouxel et al. (2006)

$s$ Calculated using Eq. S8 to achieve a steady state in the Ge mass budget (see Supp. Material),median \pm 2 S.D. based on Monte Carlo modeling that takes into account uncertainty of all parameters in this table.

$t$ Calculated using Eq. S9 (see Supp. Material), median \pm 2 S.D. based on Monte Carlo modeling that takes into account uncertainty of all parameters in this table. 


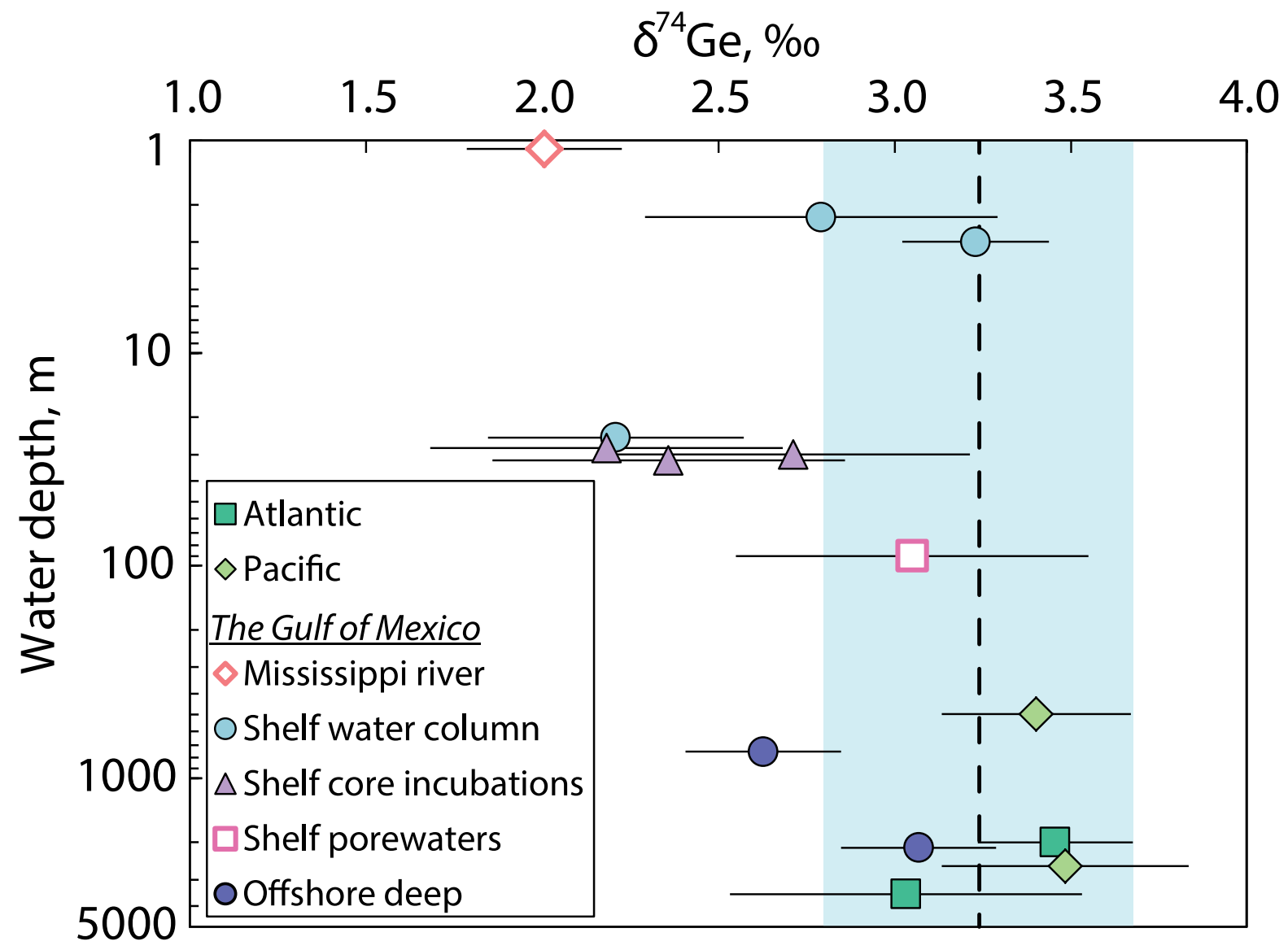

Figure 2: Seawater $\delta^{74}$ Ge measured in different locations plotted against sampling depth. The dashed black line and the light blue area indicate $3.24 \pm 0.44 \%$, the mean value of all deep ocean samples (Table 2). 


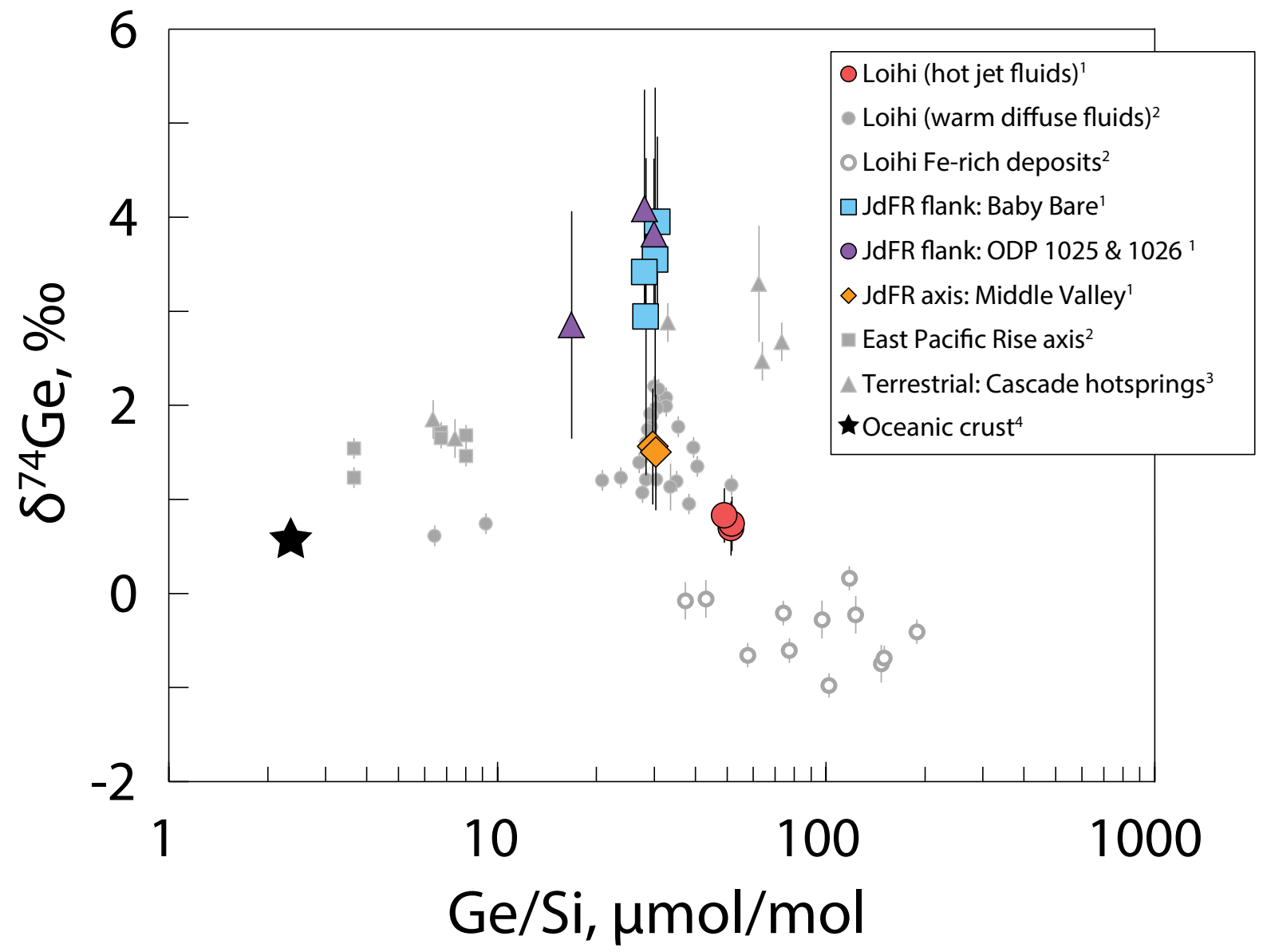

Figure 3: Summary of hydrothermal fluid $\delta^{74} \mathrm{Ge}$ values measured to date, plotted against fluid $\mathrm{Ge} / \mathrm{Si}$. Also shown are the average oceanic basalt composition and the hydrothermal Fe-rich deposits previously measured at Loihi (open circles). References: 1) this study; 2) Escoube et al. (2015); 3) Siebert et al. (2006, 2011); 4) Escoube et al. (2012). 

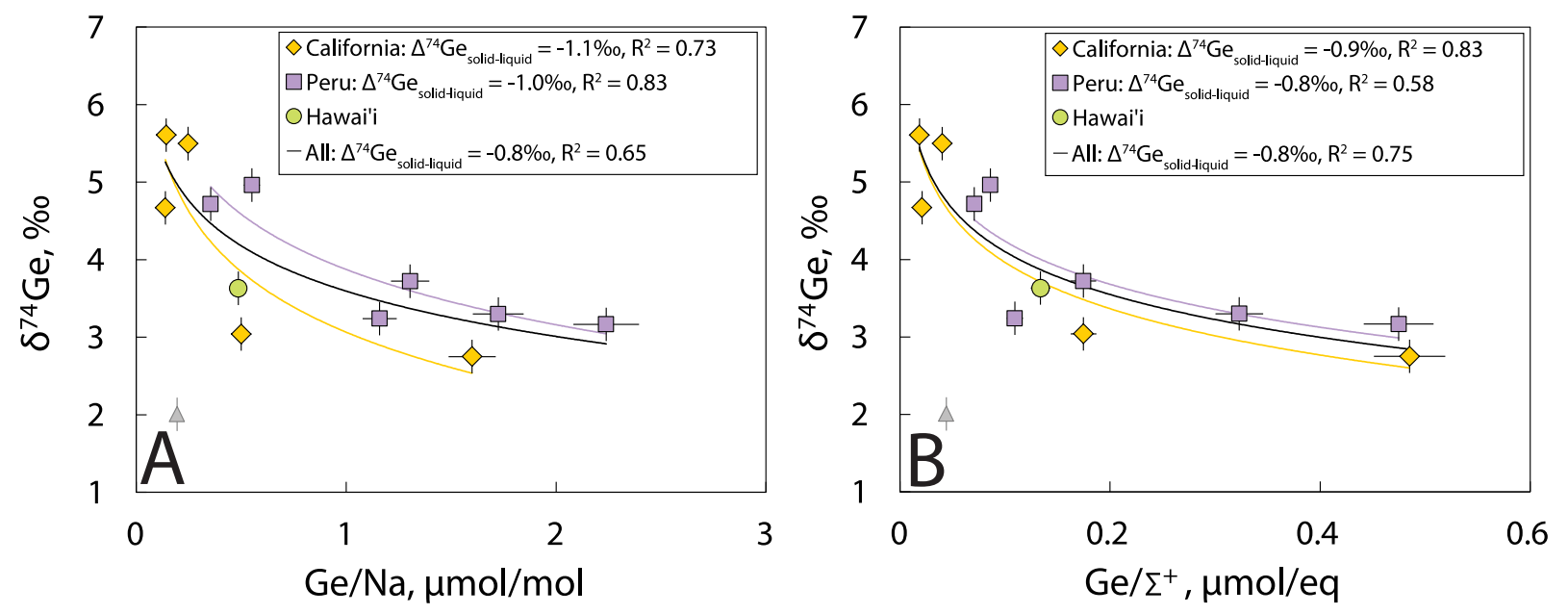

Figure 4: A: Riverine Ge isotope composition as a function of Ge/Na ratio. Symbols reflect the sampling region. The Californian streams drain the San Gabriel and Sierra Nevada mountains. Peruvian streams are all part of the Madre de Dios watershed draining the Peruvian Andes and Amazon foreland-floodplain. Grey triangle is the Mississippi sample, which was excluded from the "All" fit. Lines show the logarithm fit to each dataset and $\Delta^{74} \mathrm{Ge}$ is defined as the slope of each fit. B: Riverine Ge isotope composition as a function of $\mathrm{Ge} / \Sigma^{+}$, where $\Sigma^{+}=\mathrm{Na}^{+}+\mathrm{Ca}^{2+}+\mathrm{Mg}^{2+}+\mathrm{K}^{+}$ in $\mu \mathrm{eq} / \mathrm{L}$. All major cation concentrations are given in the Supp. Material Table S2. 


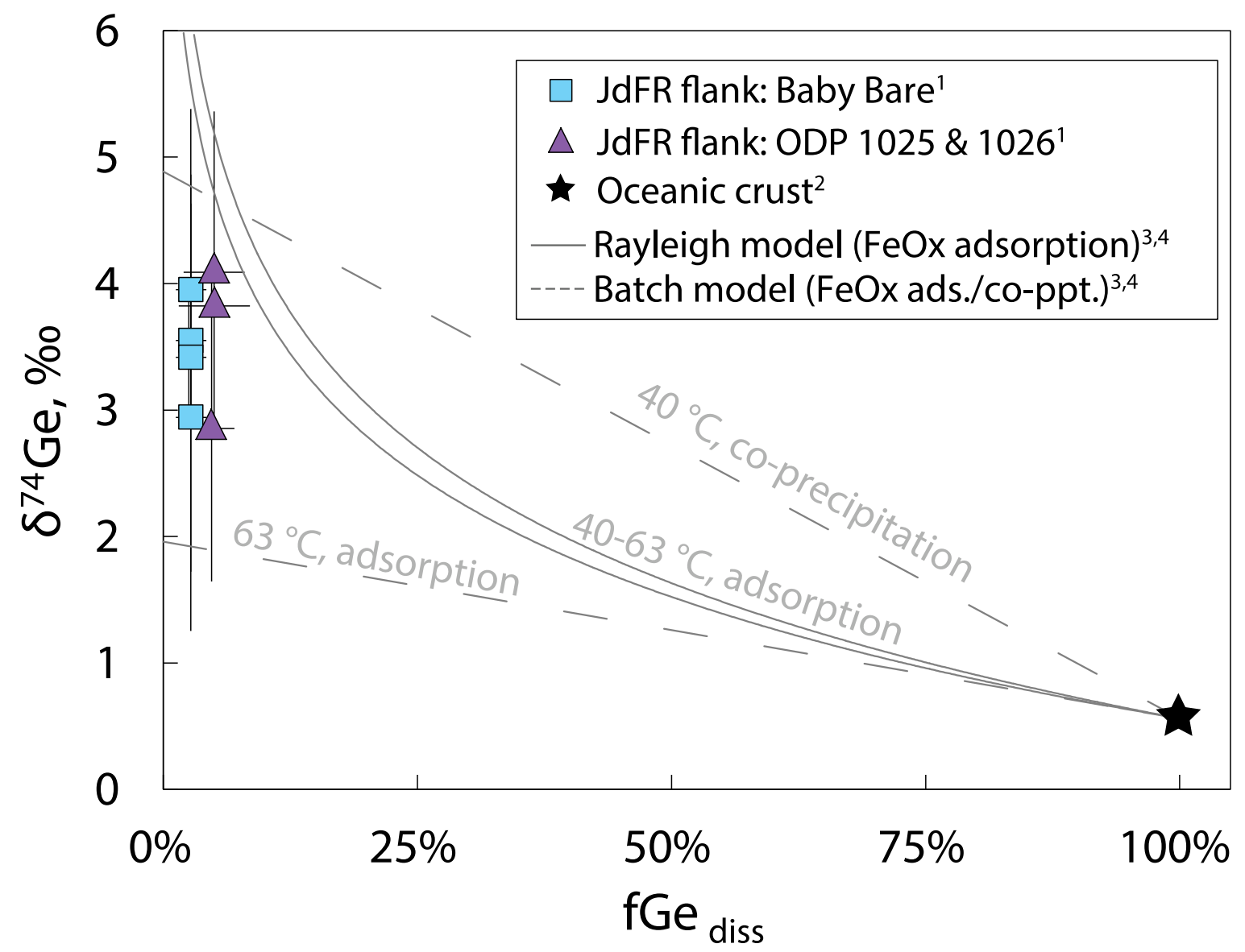

Figure 5: Measured low-temperature hydrothermal fluid $\delta^{74} \mathrm{Ge}$ plotted against $\mathrm{fGe}_{\mathrm{diss}}$, the estimated fraction of Ge remaining in solution (see Supp. Material for details). Black star marks the isotopic composition of basalt. The dashed lines show the evolution of $\delta{ }^{74} \mathrm{Ge}_{\text {fluid }}$ composition calculated using a Batch model for Ge removal with Fe-(oxy)hydroxides at basement temperatures in the area $\left(\alpha=0.9958\right.$ or $\Delta^{74} \mathrm{Ge}_{\mathrm{FeOx}}$-fluid $=-4.2 \%$ or co-precipitation at $63{ }^{\circ} \mathrm{C}$ and $\alpha=0.9984$ or $-1.6 \%$ for adsorption at $40{ }^{\circ} \mathrm{C}$ ). The black lines show $\delta{ }^{74} \mathrm{Ge}_{\text {fluid }}$ evolution for adsorption at 40 and $63{ }^{\circ} \mathrm{C}$ in a Rayleigh model $\left(\Delta^{74} \mathrm{Ge}_{\mathrm{FeOx} \text {-fluid }}=-1.6\right.$ and $-1.4 \%$, respectively). References: 1$)$ this study; 2) Escoube et al. (2012); 3) Pokrovsky et al. (2014); 4) Li and Liu (2010). 


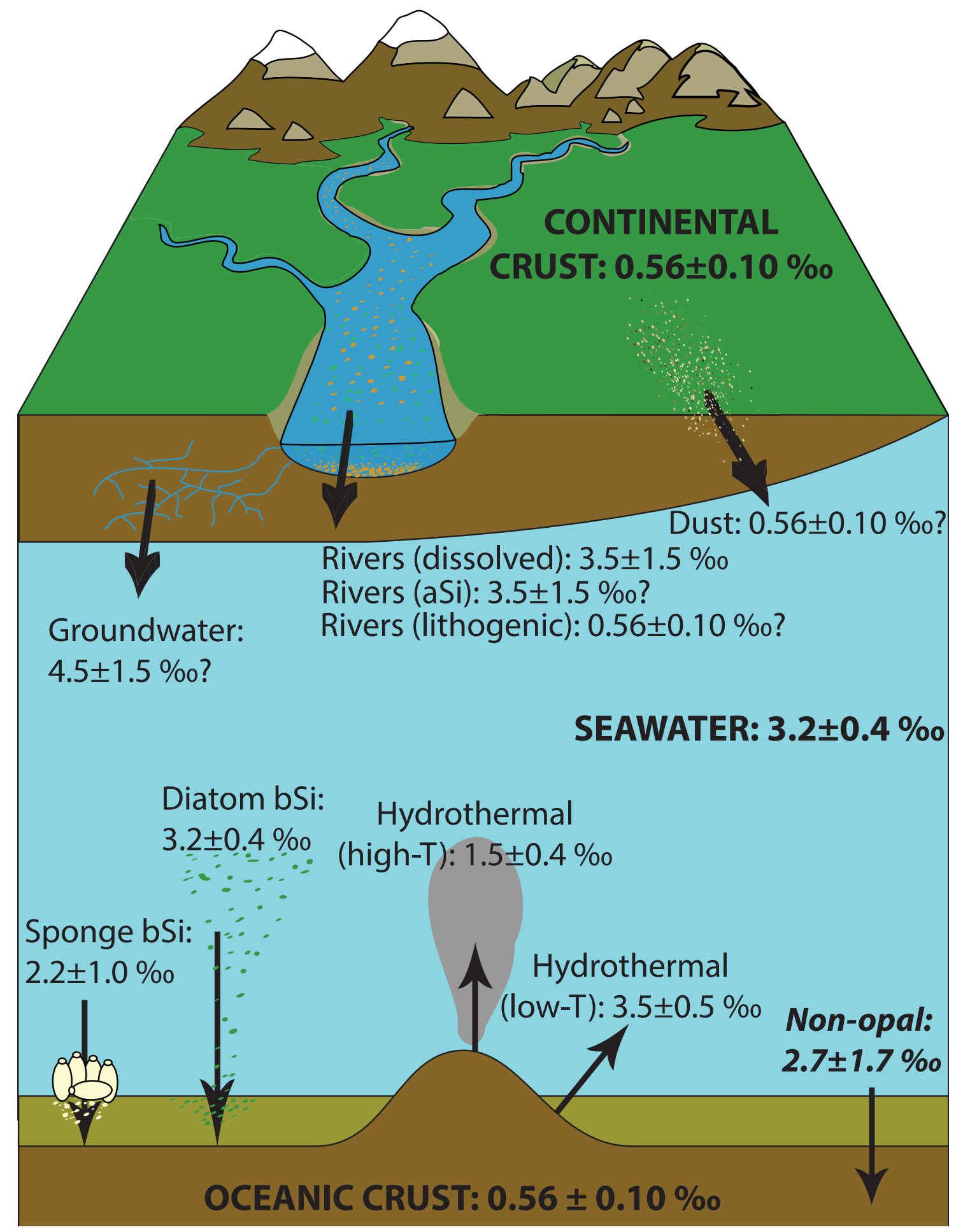

Figure 6: A summary of the oceanic Ge sources and sinks and their estimated $\delta^{74} \mathrm{Ge}$ signatures. The non-opal burial isotopic signature (in italics) was calculated assuming a steady-state Ge cycle (see Table 4 and Supp. Material). Crust values from Escoube et al. (2012), sponge bSi value from Rouxel et al. (2006), diatom bSi value based on work by Mantoura (2006). High temperature hydrothermal value from data reported here and in Escoube et al. (2015). All other values from data reported in this study. 


\section{References}

Anders A. M., Sletten R., Derry L. and Hallet B. (2003) Germanium/silicon ratios in the Copper River Basin, Alaska: Weathering and partitioning in periglacial versus glacial environments. Journal of Geophysical Research 108, 6005, doi:10.1029/2003JF000026.

Arnorsson S. (1984) Germanium in Icelandic geothermal systems. Geochimica et Cosmochimica Acta 48, 2489-2502, doi:10.1016/0016-7037(84)90300-4.

Bagard M. L., West A. J., Newman K. and Basu A. R. (2015) Lithium isotope fractionation in the Ganges-Brahmaputra floodplain and implications for groundwater impact on seawater isotopic composition. Earth and Planetary Science Letters 432, 404-414, doi:10.1016/j.epsl.2015.08.036.

Baronas J. J., Hammond D. E., Berelson W. M., McManus J. and Severmann S. (2016) Germaniumsilicon fractionation in a river-influenced continental margin: The Northern Gulf of Mexico. Geochimica et Cosmochimica Acta 178, 124-142, doi:10.1016/j.gca.2016.01.028.

Bartow J. and Pittman G. M. (1983) The Kern River Formation, Southeastern San Joaquin Valley, California. Technical Report.

Belissont R., Boiron M. C., Luais B. and Cathelineau M. (2014) LA-ICP-MS analyses of minor and trace elements and bulk Ge isotopes in zoned Ge-rich sphalerites from the Noailhac SaintSalvy deposit (France): Insights into incorporation mechanisms and ore deposition processes. Geochimica et Cosmochimica Acta 126, 518-540, doi:10.1016/j.gca.2013.10.052.

Bernstein L. (1985) Germanium geochemistry and mineralogy. Geochimica et Cosmochimica Acta 49, 2409-2422.

von Blanckenburg F., Bouchez J., Ibarra D. E. and Maher K. (2015) Stable runoff and weathering fluxes into the oceans over Quaternary climate cycles. Nature Geoscience , 1-6, doi:10.1038/ngeo2452.

Blecker S. W., King S. L., Derry L. A., Chadwick O. A., Ippolito J. A. and Kelly E. F. (2007) The ratio of germanium to silicon in plant phytoliths: Quantification of biological discrimination under controlled experimental conditions. Biogeochemistry 86, 189-199, doi:10.1007/s10533007-9154-7.

Boyle E. A., John S., Abouchami W., Adkins J. F., Echegoyen-Sanz Y., Ellwood M., Flegal A. R., Fornace K., Gallon C., Galer S., Gault-Ringold M., Lacan F., Radic A., Rehkamper M., Rouxel O., Sohrin Y., Stirling C., Thompson C., Vance D., Xue Z. and Zhao Y. (2012) GEOTRACES IC1 (BATS) contamination-prone trace element isotopes $\mathrm{Cd}, \mathrm{Fe}, \mathrm{Pb}, \mathrm{Zn}, \mathrm{Cu}$, and Mo intercalibration. Limnology and Oceanography-Methods 10, 653-665, doi:10.4319/lom.2012.10.653.

Burton J., Culkin F. and Riley J. (1959) The abundances of gallium and germanium in terrestrial materials. Geochimica et Cosmochimica Acta 16, 151-180, doi:10.1016/0016-7037(59)90052-3. 
Butterfield D. A., McDuff R. E., Franklin J. M. and Wheat C. G. (1994) Geochemistry of hydrothermal vent fluids from Middle Valley, Juan de Fuca Ridge. Proceedings of the Ocean Drilling Program, Scientific Results 139, 395-410, doi:doi:10.2973/odp.proc.sr.139.266.1994.

Caves J. K., Jost A. B., Lau K. V. and Maher K. (2016) Cenozoic carbon cycle imbalances and a variable weathering feedback. Earth and Planetary Science Letters 450, 152-163, doi:10.1016/j.eps1.2016.06.035.

Chillrud S. N., Pedrozo F., Temporetti P., Planas H. and Froelich P. (1994) Chemical weathering of phosphate and germanium in glacial meltwater streams: Effects of subglacial pyrite oxidation. Limnology and Oceanography 39, 1130-1140, doi:10.4319/lo.1994.39.5.1130.

Cornelis J. T., Delvaux B., Cardinal D., André L., Ranger J. and Opfergelt S. (2010) Tracing mechanisms controlling the release of dissolved silicon in forest soil solutions using $\mathrm{Si}$ isotopes and Ge/Si ratios. Geochimica et Cosmochimica Acta 74, 3913-3924, doi:10.1016/j.gca.2010.04.056.

De La Rocha C. L., Brzezinski M. A. and DeNiro M. J. (2000) A first look at the distribution of the stable isotopes of silicon in natural waters. Geochimica et Cosmochimica Acta 64, 2467-2477, doi:10.1016/S0016-7037(00)00373-2.

Dellinger M., Gaillardet J., Bouchez J., Calmels D., Louvat P., Dosseto A., Gorge C., Alanoca L. and Maurice L. (2015) Riverine Li isotope fractionation in the Amazon River basin controlled by the weathering regimes. Geochimica et Cosmochimica Acta 164, 71-93, doi:10.1016/j.gca.2015.04.042.

Delvigne C., Opfergelt S., Cardinal D., Delvaux B. and André L. (2009) Distinct silicon and germanium pathways in the soil-plant system: Evidence from banana and horsetail. Journal of Geophysical Research 114, G02013, doi:10.1029/2008JG000899.

Derry L. A., Kurtz A. C., Ziegler K. and Chadwick O. A. (2005) Biological control of terrestrial silica cycling and export fluxes to watersheds. Nature 433, 728-31, doi:10.1038/nature03299.

Derry L. A., Pett-Ridge J. C., Kurtz A. C. and Troester J. W. (2006) Ge/Si and 87Sr/86Sr tracers of weathering reactions and hydrologic pathways in a tropical granitoid system. Journal of Geochemical Exploration 88, 271-274, doi:10.1016/j.gexplo.2005.08.054.

Dürr H. H., Meybeck M., Hartmann J., Laruelle G. G. and Roubeix V. (2011) Global spatial distribution of natural riverine silica inputs to the coastal zone. Biogeosciences 8, 597-620, doi:10.5194/bg-8-597-2011.

Elderfield H., Wheat C. G., Mottl M. J., Monnin C. and Spiro B. (1999) Fluid and geochemical transport through oceanic crust: a transect across the eastern flank of the Juan de Fuca Ridge. Earth and Planetary Science Letters 172, 151-165, doi:Doi 10.1016/S0012-821x(99)00191-0.

Ellwood M. J., Kelly M., Maher W. A. and De Deckker P. (2006) Germanium incorporation into sponge spicules: Development of a proxy for reconstructing inorganic germanium and silicon concentrations in seawater. Earth and Planetary Science Letters 243, 749-759, doi:10.1016/j.eps1.2006.01.016. 
Escoube R., Rouxel O. J., Edwards K., Glazer B. and Donard O. F. X. (2015) Coupled Ge/Si and $\mathrm{Ge}$ isotope ratios as geochemical tracers of seafloor hydrothermal systems: Case studies at Loihi Seamount and East Pacific Rise 950’N. Geochimica et Cosmochimica Acta 167, 93-112, doi:10.1016/j.gca.2015.06.025.

Escoube R., Rouxel O. J., Luais B., Ponzevera E. and Donard O. F. (2012) An Intercomparison Study of the Germanium Isotope Composition of Geological Reference Materials. Geostandards and Geoanalytical Research 36, 149-159, doi:10.1111/j.1751-908X.2011.00135.x.

Esther T. A., Hammond D. E., Hautala S. L., Paul Johnson H., Schwartz R. J. and Paukert A. N. (2010) Evaluation of the budget for silicic acid in Cascadia Basin deep water. Deep Sea Research Part I: Oceanographic Research Papers 57, 677-686, doi:10.1016/j.dsr.2010.02.002.

Evans M. J. and Derry L. A. (2002) Quartz control of high germanium/silicon ratios in geothermal waters. Geology 30, 1019, doi:10.1130/0091-7613(2002)030<1019:QCOHGS>2.0.CO;2.

Filippelli G., Carnahan J., Derry L. and Kurtz A. (2000) Terrestrial paleorecords of Ge/Si cycling derived from lake diatoms. Chemical Geology 168, 9-26.

Foster G. L. and Vance D. (2006) Negligible glacial-interglacial variation in continental chemical weathering rates. Nature 444, 918-21, doi:10.1038/nature05365.

Frings P. J., Clymans W., Fontorbe G., De La Rocha C. and Conley D. J. (2016) The continental $\mathrm{Si}$ cycle and its impact on the ocean Si isotope budget. Chemical Geology 425, 12-36, doi:10.1016/j.chemgeo.2016.01.020.

Froelich P., Blanc V., Mortlock R., Chillrud S., Dunstan W., Udomkit A. and Peng T. (1992) River fluxes of dissolved silica to the ocean were higher during glacials: $\mathrm{Ge} / \mathrm{Si}$ in diatoms, rivers, and oceans. Paleoceanography 7, 739-767.

Froelich P., Hambrick G., Andreae M., Mortlock R. and Edmond J. (1985) The geochemistry of inorganic germanium in natural waters. Journal of Geophysical Research 90, 1133-1141.

Froelich P., Mortlock R. and Shemesh A. (1989) Inorganic germanium and silica in the Indian Ocean: biological fractionation during (Ge/Si) Opal formation. Global Biogeochemical Cycles 3, 79-88.

Froelich P. N., Hambrick G. A., Kaul L. W., Byrd J. T. and Lecointe O. (1985) Geochemical behavior of inorganic geranium in an unperturbed estuary. Geochimica et Cosmochimica Acta 49, 519-524.

Froelich P. N. and Lesley P. (2001) Tracing Germanium Contamination From Coal-Fired Power Plants Down The Chattahoochee-Apalachicola River : Implications For The Toxic Metalloids Arsenic And Selenium, in: Proceedings of the 2001 Georgia Water Resources Conference.

Geilert S., Vroon P. Z., Keller N. S., Gudbrandsson S., Stefánsson A. and van Bergen M. J. (2015) Silicon isotope fractionation during silica precipitation from hot-spring waters: Evidence from the Geysir geothermal field, Iceland. Geochimica et Cosmochimica Acta 164, 403-427, doi:10.1016/j.gca.2015.05.043. 
Geilert S., Vroon P. Z., Roerdink D. L., Van Cappellen P. and van Bergen M. J. (2014) Silicon isotope fractionation during abiotic silica precipitation at low temperatures: Inferences from flow-through experiments. Geochimica et Cosmochimica Acta 142, 95-114, doi:10.1016/j.gca.2014.07.003.

Georg R., Reynolds B., West A., Burton K. and Halliday A. (2007) Silicon isotope variations accompanying basalt weathering in Iceland. Earth and Planetary Science Letters 261, 476-490, doi:10.1016/j.eps1.2007.07.004.

Glazer B. T. and Rouxel O. J. (2009) Redox Speciation and Distribution within Diverse Irondominated Microbial Habitats at Loihi Seamount. Geomicrobiology Journal 26, 606-622, doi:10.1080/01490450903263392.

Hammond D. E., Cummins K. M., McManus J., Berelson W. M., Smith G. and Spagnoli F. (2004) Methods for measuring benthic nutrient flux on the California Margin: Comparing shipboard core incubations to in situ lander results. Limnology And Oceanography-Methods 2, 146-159.

Hammond D. E., McManus J. and Berelson W. M. (2004) Oceanic germanium/silicon ratios: Evaluation of the potential overprint of temperature on weathering signals. Paleoceanography 19, PA2016, doi:10.1029/2003PA000940.

Hammond D. E., McManus J., Berelson W. M., Meredith C., Klinkhammer P. and Coale K. (2000) Diagenetic fractionation of Ge and Si in reducing sediments: the missing Ge sink and a possible mechanism to cause glacial/interglacial variations in oceanic Ge/Si. Geochimica et Cosmochimica Acta 64, 2453-2465.

Hazen R. M. and Finger L. W. (1981) Bulk moduli and high-pressure crystal structures of rutiletype compounds. Journal of Physics and Chemistry of Solids 42, 143-151, doi:10.1016/00223697(81)90074-3.

Hughes H., Sondag F., Santos R., André L. and Cardinal D. (2013) The riverine silicon isotope composition of the Amazon Basin. Geochimica et Cosmochimica Acta 121, 637-651, doi:10.1016/j.gca.2013.07.040.

Huh Y., Chan L. H. and Edmond J. M. (2001) Lithium isotopes as a probe of weathering processes: Orinoco River. Earth and Planetary Science Letters 194, 189-199, doi:10.1016/S0012$821 \mathrm{X}(01) 00523-4$.

Huybers P. and Langmuir C. H. (2017) Delayed CO2 emissions from mid-ocean ridge volcanism as a possible cause of late-Pleistocene glacial cycles. Earth and Planetary Science Letters $\mathbf{4 5 7}$, 238-249, doi:10.1016/j.eps1.2016.09.021.

King S., Froelich P. and Jahnke R. (2000) Early diagenesis of germanium in sediments of the Antarctic South Atlantic: in search of the missing Ge sink. Geochimica et Cosmochimica Acta 64, 1375-1390.

Klapdor-Kleingrothaus H. V., Dietz A., Baudis L., Heusser G., Krivosheina I. V., Majorovits B., Paes H., Strecker H., Alexeev V., Balysh A., Bakalyarov A., Belyaev S. T., Lebedev V. I. and Zhukov S. (2001) Latest results from the HEIDELBERG-MOSCOW double beta decay experiment. European Physical Journal A 12, 147-154, doi:10.1007/s100500170022. 
Kurtz A., Derry L. and Chadwick O. (2002) Germanium-silicon fractionation in the weathering environment. Geochimica et Cosmochimica Acta 66, 1525-1537.

Kurtz A. C., Lugolobi F. and Salvucci G. (2011) Germanium-silicon as a flow path tracer: Application to the Rio Icacos watershed. Water Resources Research 47, W06516, doi:10.1029/2010WR009853.

de Laeter J. R., Böhlke J. K., De Bièvre P., Hidaka H., Peiser H. S., Rosman K. J. R. and Taylor P. D. P. (2003) Atomic weights of the elements. Review 2000 (IUPAC Technical Report). Technical Report 6, doi:10.1351/pac200375060683.

Lewis B., Andreae M. and Froelich P. (1989) Sources and sinks of methylgermanium in natural waters. Marine Chemistry 27, 179-200.

Li G. and Elderfield H. (2013) Evolution of carbon cycle over the past 100 million years. Geochimica et Cosmochimica Acta 103, 11-25, doi:10.1016/j.gca.2012.10.014.

Li X., Zhao H., Tang M. and Liu Y. (2009) Theoretical prediction for several important equilibrium Ge isotope fractionation factors and geological implications. Earth and Planetary Science Letters 287, 1-11, doi:10.1016/j.epsl.2009.07.027.

Li X. F. and Liu Y. (2010) First-principles study of Ge isotope fractionation during adsorption onto Fe(III)-oxyhydroxide surfaces. Chemical Geology 278, 15-22, doi:10.1016/j.chemgeo.2010.05.008.

Lugolobi F., Kurtz A. C. and Derry L. A. (2010) Germanium-silicon fractionation in a tropical, granitic weathering environment. Geochimica et Cosmochimica Acta 74, 1294-1308, doi:10.1016/j.gca.2009.11.027.

Lund D. C., Asimow P. D., Farley K. A., Rooney T. O., Seeley E., Jackson E. W. and Durham Z. M. (2016) Enhanced East Pacific Rise hydrothermal activity during the last two glacial terminations. Science 351, 478-482, doi:10.1126/science.aad4296.

Mantoura S. C. (2006) Development and Application of Opal Based Paleoceanographic Proxies. Ph.D. thesis University of Cambridge.

McManus J., Hammond D. E., Cummins K., Klinkhammer G. P. and Berelson W. M. (2003) Diagenetic Ge-Si fractionation in continental margin environments: further evidence for a nonopal Ge sink. Geochimica et Cosmochimica Acta 67, 4545-4557, doi:10.1016/S0016-7037(03)00385-5.

Meek K., Derry L., Sparks J. and Cathles L. (2016) 87Sr/86Sr, Ca/Sr, and Ge/Si ratios as tracers of solute sources and biogeochemical cycling at a temperate forested shale catchment, central Pennsylvania, USA. Chemical Geology, doi:10.1016/j.chemgeo.2016.04.026.

Michalopoulos P. and Aller R. C. (2004) Early diagenesis of biogenic silica in the Amazon delta: alteration, authigenic clay formation, and storage. Geochimica et Cosmochimica Acta 68 , 1061-1085, doi:10.1016/j.gca.2003.07.018. 
Misra S. and Froelich P. N. (2012) Lithium isotope history of Cenozoic seawater: changes in silicate weathering and reverse weathering. Science 335, 818-823, doi:10.1126/science.1214697.

Mortlock R., Charles C., Froelich P., Zibello M., Saltzman J., Hays J. and Burckle L. (1991) Evidence for lower productivity in the Antarctic Ocean during the last glaciation. Nature 351, 220-223.

Mortlock R. and Froelich P. (1986) Hydrothermal germanium over the southern East Pacific Rise. Science 231, 43-45.

Mortlock R. and Froelich P. (1987) Continental weathering of germanium: Ge/Si in the global river discharge. Geochimica et Cosmochimica Acta 51, 2075-2082.

Mortlock R. and Froelich P. (1996) Determination of germanium by isotope dilution-hydride generation inductively coupled plasma mass spectrometry. Analytica Chimica Acta 332, 277284.

Mortlock R. A., Froelich P. N., Feely R. A., Massoth G. J., Butterfield D. A. and Lupton J. E. (1993) Silica and germanium in Pacific Ocean hydrothermal vents and plumes. Earth and Planetary Science Letters 119, 365-378, doi:10.1016/0012-821X(93)90144-X.

Mottl M. J. and Holland H. D. (1978) Chemical exchange during hydrothermal alteration of basalt by seawater-I. Experimental results for major and minor components of seawater. Geochimica et Cosmochimica Acta 42, 1103-1115, doi:10.1016/0016-7037(78)90107-2.

Mottl M. J., Wheat G., Baker E., Becker N., Davis E., Feely R., Grehan A., Kadko D., Lilley M., Massoth G., Moyer C. and Sansone F. (1998) Warm springs discovered on $3.5 \mathrm{Ma}$ oceanic crust, eastern flank of the Juan de Fuca Ridge. Geology 26, 51-54, doi:10.1130/00917613(1998)026<0051:WSDOMO>2.3.CO;2.

Mullin J. and Riley J. (1955) The colorimetric determination of silicate with special reference to sea and natural waters. Analytica Chimica Acta 12, 162-175.

Murnane R. and Stallard R. (1990) Germanium and silicon in rivers of the Orinoco drainage basin. Nature 344, 749-752.

Oelze M., von Blanckenburg F., Hoellen D., Dietzel M. and Bouchez J. (2014) Si stable isotope fractionation during adsorption and the competition between kinetic and equilibrium isotope fractionation: Implications for weathering systems. Chemical Geology 380, 161-171, doi:10.1016/j.chemgeo.2014.04.027.

Opfergelt S., Burton K., Pogge von Strandmann P., Gislason S. and Halliday A. (2013) Corrigendum to: Riverine silicon isotope variations in glaciated basaltic terrains: Implications for the $\mathrm{Si}$ delivery to the ocean over glacial-interglacial intervals [Earth Planet. Sci. Lett. 369-370 (2013) 211-219]. Earth and Planetary Science Letters 375, 451-452, doi:10.1016/j.epsl.2013.07.010.

Opfergelt S., Burton K., Pogge von Strandmann P., Gislason S. and Halliday A. (2013) Riverine silicon isotope variations in glaciated basaltic terrains: Implications for the Si delivery to the ocean over glacial-interglacial intervals. Earth and Planetary Science Letters 369-370, 211-219, doi:10.1016/j.eps1.2013.03.025. 
Opfergelt S., Cardinal D., Henriet C., André L. and Delvaux B. (2006) Silicon isotope fractionation between plant parts in banana: In situ vs. in vitro. Journal of Geochemical Exploration 88, 224-227, doi:10.1016/j.gexplo.2005.08.044.

Pokrovski G. and Schott J. (1998) Thermodynamic properties of aqueous Ge (IV) hydroxide complexes from 25 to $350 \mathrm{C}$ : implications for the behavior of germanium and the $\mathrm{Ge} / \mathrm{Si}$ ratio in hydrothermal. Geochimica et cosmochimica acta 62, 1631-1642.

Pokrovski G. S., Roux J., Hazemann J. L. and Testemale D. (2005) An X-ray absorption spectroscopy study of argutite solubility and aqueous Ge(IV) speciation in hydrothermal fluids to $500{ }^{\circ} \mathrm{C}$ and 400 bar. Chemical Geology 217, 127-145, doi:10.1016/j.chemgeo.2005.01.006.

Pokrovsky O., Pokrovski G., Schott J. and Galy A. (2006) Experimental study of germanium adsorption on goethite and germanium coprecipitation with iron hydroxide: X-ray absorption fine structure and macroscopic characterization. Geochimica et Cosmochimica Acta 70, 33253341, doi:10.1016/j.gca.2006.04.012.

Pokrovsky O. S., Galy A., Schott J., Pokrovski G. S. and Mantoura S. (2014) Germanium isotope fractionation during $\mathrm{Ge}$ adsorption on goethite and its coprecipitation with Fe oxy(hydr)oxides. Geochimica et Cosmochimica Acta 131, 138-149, doi:10.1016/j.gca.2014.01.023.

Ponton C., West A. J., Feakins S. J. and Galy V. (2014) Leaf wax biomarkers in transit record river catchment composition. Geophysical Research Letters 41, 6420-6427, doi:10.1002/2014GL061328.

Qi H. W., Rouxel O., Hu R. Z., Bi X. W. and Wen H. J. (2011) Germanium isotopic systematics in Ge-rich coal from the Lincang Ge deposit, Yunnan, Southwestern China. Chemical Geology 286, 252-265, doi:10.1016/j.chemgeo.2011.05.011.

Rahman S., Aller R. C. and Cochran J. K. (2016) Cosmogenic 32 Si as a tracer of biogenic silica burial and diagenesis: Major deltaic sinks in the silica cycle. Geophysical Research Letters 43, 7124-7132, doi:10.1002/2016GL069929.

Raymo M. and Ruddiman W. (1992) Tectonic forcing of late Cenozoic climate. Nature 359, $117-122$.

Rouxel O., Galy A. and Elderfield H. (2006) Germanium isotopic variations in igneous rocks and marine sediments. Geochimica et Cosmochimica Acta 70, 3387-3400, doi:10.1016/j.gca.2006.04.025.

Scribner A. M., Kurtz A. C. and Chadwick O. A. (2006) Germanium sequestration by soil: Targeting the roles of secondary clays and Fe-oxyhydroxides. Earth and Planetary Science Letters 243, 760-770, doi:10.1016/j.epsl.2006.01.051.

Sedwick P., McMurtry G. and Macdougall J. (1992) Chemistry of hydrothermal solutions from Pele's Vents, Loihi Seamount, Hawaii. Geochimica et Cosmochimica Acta 56, 3643-3667, doi:10.1016/0016-7037(92)90159-G. 
Seyfried W. E. (1987) Experimental and theoretical constraints on hydrothermal alteration processes at mid- ocean ridges. Annual review of earth and planetary sciences. Vol. 15 5, 317-335.

Shemesh A., Mortlock R. A. and Froelich P. N. (1989) Late cenozoic Ge/Si record of marine biogenic opal: Implications for variations of riverine fluxes to the ocean. Paleoceanography 4, 221-234.

Siebert C., Hammond D. E., Ross A. and McManus J. (2011) Erratum to C. Siebert, A. Ross and J. McManus (2006) "Germanium isotope measurements of high-temperature geothermal fluids using double-spike hydride generation MC-ICP-MS", Geochimica et Cosmochimica Acta 70, 3986-3995. Geochimica et Cosmochimica Acta 75, 6267-6269, doi:10.1016/j.gca.2011.07.032.

Siebert C., Ross A. and McManus J. (2006) Germanium isotope measurements of high-temperature geothermal fluids using double-spike hydride generation MC-ICP-MS. Geochimica et Cosmochimica Acta 70, 3986-3995, doi:10.1016/j.gca.2006.06.007.

Pogge von Strandmann P. A. E. and Henderson G. M. (2015) The Li isotope response to mountain uplift. Geology 43, 67-70, doi:10.1130/G36162.1.

Pogge von Strandmann P. A. E., Opfergelt S., Lai Y. J., Sigfússon B., Gislason S. R. and Burton K. W. (2012) Lithium, magnesium and silicon isotope behaviour accompanying weathering in a basaltic soil and pore water profile in Iceland. Earth and Planetary Science Letters 339-340, 11-23, doi:10.1016/j.epsl.2012.05.035.

Sutton J., Ellwood M. J., Maher W. A. and Croot P. L. (2010) Oceanic distribution of inorganic germanium relative to silicon: Germanium discrimination by diatoms. Global Biogeochemical Cycles 24, GB2017, doi:10.1029/2009GB003689.

Tom McGlothlin (1944) General Geology of Mississippi. AAPG Bulletin 28, 29-62, doi:10.1306/3D933638-16B1-11D7-8645000102C1865D.

Treguer P., Nelson D. M., Vanbennekom A. J., Demaster D. J., Leynaert A. and Queguiner B. (1995) The Silica Balance in the World Ocean - a Reestimate. Science 268, 375-379, doi:10.1126/science.268.5209.375.

Tréguer P. J. and De La Rocha C. L. (2013) The World Ocean Silica Cycle. Annual review of marine science 5, 477-501, doi:10.1146/annurev-marine-121211-172346.

Vance D., Teagle D. A. H. and Foster G. L. (2009) Variable Quaternary chemical weathering fluxes and imbalances in marine geochemical budgets. Nature 458, 493-6, doi:10.1038/nature07828.

Vigier N., Decarreau A., Millot R., Carignan J., Petit S. and France-Lanord C. (2008) Quantifying $\mathrm{Li}$ isotope fractionation during smectite formation and implications for the Li cycle. Geochimica et Cosmochimica Acta 72, 780-792, doi:10.1016/j.gca.2007.11.011.

Von Damm K. L., Bischoff J. L. and Rosenbauer R. J. (1991) Quartz solubility in hydrothermal seawater; an experimental study and equation describing quartz solubility for up to $0.5 \mathrm{M} \mathrm{NaCl}$ solutions. American Journal of Science 291, 977-1007, doi:10.2475/ajs.291.10.977. 
West A., Galy A. and Bickle M. (2005) Tectonic and climatic controls on silicate weathering. Earth and Planetary Science Letters 235, 211-228, doi:10.1016/j.eps1.2005.03.020.

Wheat C. G., Jannasch H. W., Kastner M., Plant J. N., DeCarlo E. H. and Lebon G. (2004) Venting formation fluids from deep-sea boreholes in a ridge flank setting: ODP Sites 1025 and 1026. Geochemistry, Geophysics, Geosystems 5, doi:10.1029/2004GC000710.

Wheat C. G., Jannasch H. W., Plant J. N., Moyer C. L., Sansone F. J. and McMurtry G. M. (2000) Continuous sampling of hydrothermal fluids from Loihi Seamount after the 1996 event. Journal of Geophysical Research 105, 19353, doi:10.1029/2000JB900088.

Wheat C. G. and McManus J. (2005) The potential role of ridge-flank hydrothermal systems on oceanic germanium and silicon balances. Geochimica et Cosmochimica Acta 69, 2021-2029, doi:10.1016/j.gca.2004.05.046.

Wheat C. G. and McManus J. (2008) Germanium in mid-ocean ridge flank hydrothermal fluids. Geochemistry, Geophysics, Geosystems 9, 1-16, doi:10.1029/2007GC001892.

Wheat C. G. and Mottl M. J. (2000) Composition of pore and spring waters from Baby Bare: Global implications of geochemical fluxes from a ridge flank hydrothermal system. Geochimica et Cosmochimica Acta 64, 629-642, doi:10.1016/S0016-7037(99)00347-6.

Wheat C. G., Mottl M. J. and Rudnicki M. (2002) Trace element and REE composition of a lowtemperature ridge-flank hydrothermal spring. Geochimica et Cosmochimica Acta 66, 3693-3705, doi:10.1016/S0016-7037(02)00894-3.

Wilkens R. H., Fryer G. J. and Karsten J. (1991) Evolution of porosity and seismic structure of upper oceanic crust: Importance of aspect ratios. Journal of Geophysical Research 96, 17981, doi:10.1029/91JB01454.

Wimpenny J., Colla C. A., Yu P., Yin Q. Z., Rustad J. R. and Casey W. H. (2015) Lithium isotope fractionation during uptake by gibbsite. Geochimica et Cosmochimica Acta 168, 133-150, doi:10.1016/j.gca.2015.07.011.

Wimpenny J., Gíslason S. R., James R. H., Gannoun A., Pogge Von Strandmann P. A. E. and Burton K. W. (2010) The behaviour of $\mathrm{Li}$ and $\mathrm{Mg}$ isotopes during primary phase dissolution and secondary mineral formation in basalt. Geochimica et Cosmochimica Acta 74, 5259-5279, doi:10.1016/j.gca.2010.06.028.

Ziegler K., Chadwick O. A., Brzezinski M. A. and Kelly E. F. (2005) Natural variations of ??30Si ratios during progressive basalt weathering, Hawaiian Islands. Geochimica et Cosmochimica Acta 69, 4597-4610, doi:10.1016/j.gca.2005.05.008. 